\title{
Ice-oxyhydrocarbon interactions in the troposphere
}

\author{
William A. Huffman \\ Huffman Laboratories, Incorporated, Golden, Colorado, USA
}

Jefferson R. Snider

Department of Atmospheric Sciences, University of Wyoming, Laramie, Wyoming, USA

Received 14 May 2003; revised 21 August 2003; accepted 6 October 2003; published 8 January 2004.

[1] Both surface and volume uptake can contribute to the removal of tropospheric gases by ice-phase precipitation and cloud particles. These processes were evaluated by depositing ice in the presence of several gaseous oxyhydrocarbons and analyzing the chemical composition of the deposit. Acetone, methanol, ethanol, n-propanol, n-butanol, tert-butanol, cyclohexanol, and toluene were tested. Volume uptake appears to be the dominant process, and results are presented as temperature-dependent volume uptake coefficients. When extrapolated to $0^{\circ} \mathrm{C}$, the volume uptake coefficients are at least a factor of two smaller than predictions based on gas partitioning into liquid water. Volume uptake coefficients at $-10^{\circ} \mathrm{C}$ are $5-2 \mathrm{~mol} \mathrm{~m}^{-3} \mathrm{~Pa}^{-1}$ for the alkanols (i.e., $5 \times 10^{2}-2 \times$ $\left.10^{2} \mathrm{~mol} \mathrm{~L}^{-1} \mathrm{~atm}^{-1}\right), 0.8 \mathrm{~mol} \mathrm{~m} \mathrm{~Pa}^{-1}$ for acetone, and $0.01 \mathrm{~mol} \mathrm{~m}^{-3} \mathrm{~Pa}^{-1}$ for toluene. Further, our analysis indicates that the alkanols weaken water-water bonding when incorporated into ice. This assertion is based on the positive temperature dependence of the alkanol volume uptake coefficients and is corroborated by indirect estimates of the effect of the alkanols on ice saturation vapor pressure. Since the observed volume uptake coefficients do not exceed the $10 \mathrm{~mol} \mathrm{~m}^{-3} \mathrm{~Pa}^{-1}$ threshold proposed by Crutzen and Lawrence [2000], our results indicate that the incorporation of the studied compounds into vapor-deposited ice is not a substantial atmospheric removal process. INDEX TERMS: 0315 Atmospheric Composition and Structure: Biosphere/atmosphere interactions; 0320 Atmospheric Composition and Structure: Cloud physics and chemistry; 1694 Global Change: Instruments and techniques; KEYWORDS: snow, oxygenated hydrocarbons, incorporation processes, cloud scavenging

Citation: Huffman, W. A., and J. R. Snider (2004), Ice-oxyhydrocarbon interactions in the troposphere, J. Geophys. Res., 109, D01302, doi:10.1029/2003JD003778.

\section{Introduction}

[2] The scavenging of atmospheric constituents by precipitation is an important removal process for gaseous amines, inorganic acids and oxygenated organics. Henry's law coefficients are available for describing the interaction of these compounds with liquid water (i.e., cloud water and rain) [e.g., Benkelberg et al., 1995] but considerably less is known about situations involving solid-phase precipitation (i.e., snow, graupel and hail). Confounding is the fact that two ice growth mechanisms operate in the atmosphere: (1) the collection of supercooled cloud droplets by ice (riming) and (2) vapor-to-ice growth by diffusion. We will refer to the latter process as water vapor depositional growth. Rarely do either of these processes operate exclusively and in a broad variety of cloud systems, both at high and low latitude, both mechanisms can contribute to the precipitated water flux [Hobbs, 1978; Houze, 1993]. Variability of precipitation type, the complex shape of ice particles, gas/ice interactions occurring both on ice hydro-

Copyright 2004 by the American Geophysical Union. 0148-0227/04/2003JD003778 meteor surfaces and within their interior and incomplete understanding of how gas properties influence the gas/ice interaction all contribute uncertainty to estimates of the contaminant flux carried by solid-phase precipitation. This study presents measurements of gas/ice interactions during vapor depositional growth, and thus advances quantitative understanding of that process.

[3] Experiments designed to evaluate gas interactions with ice are logically divided into "growing ice" and "static ice" studies. By the latter we imply situations where no net deposition or sublimation is occurring. The laboratory work of Conklin et al. [1993] and Goss [1993] fall into the static ice category. Both studies focused on temperatures typical of the lower atmosphere, and with the exception of the measurements made by Conklin et al. [1993] at $T>-10^{\circ} \mathrm{C}$ both reveal an inverse relationship between surface or volume uptake and temperature. While surface uptake is the dominant process in the studies conducted by Goss [1993], the ice/ $\mathrm{H}_{2} \mathrm{O}_{2}$ interaction examined by Conklin et al. [1993] is predominately one of volume uptake with a secondary contribution from two plausible surface processes, (1) bonding to the air-ice interface or (2) uptake into a liquid solution phase coexisting with ice. At $T>-10^{\circ} \mathrm{C}$ 
Conklin et al. [1993] show that $\mathrm{H}_{2} \mathrm{O}_{2}$ uptake increases with increasing temperature. It was not clarified whether the uptake reversal reflects an enlargement of the liquid solution volume, or an increased affinity of ice for $\mathrm{H}_{2} \mathrm{O}_{2}$, as temperature tends toward $0^{\circ} \mathrm{C}$. Goss [1993] showed that ice prepared by freezing salt solutions (either $\mathrm{H}_{2} \mathrm{O} / \mathrm{CaSO}_{4}$ or $\mathrm{H}_{2} \mathrm{O} / \mathrm{NaCl}$ ) had a lower affinity for acetone, and also a lower affinity for several less polar organic compounds, compared to ice prepared without salts. Their observations indicate that uptake is not enhanced by uptake into a liquid solution phase coexisting with the ice, although the apparatus and techniques employed by Goss [1993] may not be suited for quantifying that process.

[4] Valdez et al. [1989] investigated the volume uptake of gaseous $\mathrm{SO}_{2}$ during ice depositional growth. They concluded that this process can be an important atmospheric mechanism for $\mathrm{SO}_{2}$ removal, particularly in high-latitude and high-altitude cloud systems, but their experiments evaluated $\mathrm{SO}_{2}$ volume uptake at only one temperature $\left(-15^{\circ} \mathrm{C}\right)$. Mitra et al. [1990] made similar measurements but reported $\mathrm{SO}_{2}$ volume uptakes a factor of 15 smaller than that reported by Valdez et al. [1989]. Mitra et al. [1990] did not discuss this difference. Dominé and Thibert [1996] report measurements of the solubility of $\mathrm{HCl}$ and $\mathrm{HNO}_{3}$ in laboratory ice and their concentrations in polar snow. In the case of $\mathrm{HNO}_{3}$, their work confirms that equilibrium treatments of both surface and volume uptake correctly predict the amount in snow, but for $\mathrm{HCl}$ they show that the kinetics of both $\mathrm{H}_{2} \mathrm{O}$ and $\mathrm{HCl}$ deposition and solid state diffusion are important determinants of snow concentrations. The absence of either surface or volume uptake measurements for species other than a few inorganic species (e.g., $\mathrm{H}_{2} \mathrm{O}_{2}$, $\mathrm{SO}_{2}, \mathrm{HCl}$, and $\mathrm{HNO}_{3}$ ) provides the main motivation for this study.

[5] Laboratory studies have shown that a liquid layer can exist on ice surfaces exposed to water soluble gases or on ice produced by freezing solutions containing electrolytes [Conklin and Bales, 1993; Knight, 1996]. During our experiments we grew ice by depositing water vapor from ambient air which was spiked with the analytes of interest. No attempt was made to eliminate ambient water soluble gases expected to enhance the volume of solution associated with a surface liquid layer. We therefore presume that the layer was present. How can this layer influence analyte uptake? First, because the layer is thought to be reformed rapidly (layer $\mathrm{H}_{2} \mathrm{O}$ molecule residence times are $\sim 30 \mu \mathrm{s}$ if calculated using kinetic theory [Reif, 1965] and assuming a $100 \mathrm{~nm}$ layer thickness [Conklin and Bales, 1993]) it is expected that gaseous analytes are codissolved in the surface liquid layer. Second, ice forming at the expense of layered $\mathrm{H}_{2} \mathrm{O}$ molecules allows for the possibility that the analytes are incorporated into an impure ice phase we will refer to as a solid solution. Assuming equilibrium, the following relationship describes the interaction:

$$
K_{g, s \mathrm{~s}}=K_{g, l} K_{l, s s} .
$$

Two of these equilibrium coefficients $\left(K_{g, s s}\right.$ and $\left.K_{g, l}\right)$ relate analyte concentrations, in the ice solid solution (ss) and liquid water $(l)$ phases, to analyte partial pressure in the gas phase $(g)$. The third equilibrium coefficient $\left(K_{l, \mathrm{ss}}\right)$ relates concentrations in the li ater $(l)$ and solid solution (ss) phases. Using measurements of $K_{g, l}$ and $K_{l, \mathrm{ss}}$, equation (1) has been used to predict $\mathrm{HCl}$ uptake in ice clouds. Hanson and Mauersberger [1990] showed that prior determinations of $K_{l, \mathrm{ss}}$ for $\mathrm{HCl}$ were in error and lead to overestimates of the partitioning of gaseous $\mathrm{HCl}$ into ice $\left(K_{g, \mathrm{ss}}\right)$ under stratospheric conditions. The work of Hanson and Mauersberger [1990] highlights the need for redundant checks of $K_{g, s s}, K_{g, l}$, and $K_{l, \mathrm{ss}}$. Here we report direct measurements of $K_{g, \mathrm{ss}}$ for oxyhydrocarbons and toluene interacting with vapordeposited ice under tropospheric conditions. Hereinafter, we will refer to $K_{g, s s}$ as the volume uptake coefficient.

[6] We selected five of the eight noncyclic $\mathrm{C}_{1}-\mathrm{C}_{4}$ alkanols, cyclohexanol, acetone and toluene for this study. When expressed in terms of polarizability and hydrogen bond donor acidity the $\mathrm{C}_{1}-\mathrm{C}_{6}$ alkanols differ by less than $25 \%$ [Kamlet et al., 1988]. Substantially larger differences are seen in tabulations of the Van der Waals volumes for these compounds [Kamlet et al., 1988]. We therefore investigated the plausibility that ice uptake of the five selected $\mathrm{C}_{1}-\mathrm{C}_{4}$ alkanols, and cyclohexanol, is controlled by molecular size. Acetone represents a class of compounds (ketones) that can only participate in hydrogen bonding as a hydrogen bond acceptor. Hence we have also compared acetone uptakes to those for the six selected alkanols with the view toward delineating the importance of acceptor-only hydrogen bonding versus donor/acceptor hydrogen bonding. We also report measurements of the uptake of toluene. This compound is characterized by a vapor pressure comparable to that of the $\mathrm{C}_{4}$ alkanols and was chosen as a comparison compound which is not capable of functioning as a hydrogen bond donor and only weakly as an acceptor. All of the selected compounds are stable in water on timescales required by our measurement protocol.

[7] Considerable attention has been focused on the atmospheric cycles of the alkanols [Goldan et al., 1995] and acetone [Singh et al., 1994]. These compounds are members of a larger group that is commonly called oxygenates. The field data show that oxygenates constitute a substantial, but poorly characterized, fraction of gaseous nonmethane organic carbon. In particular, the alkanols and acetone have chemical lifetimes which are measured in tens of days, can undergo long-range transport and are thought to play significant roles in modulating the formation of ozone and peroxyacetylnitrate in the free troposphere [Singh et al., 1994]. The magnitude of this impact may be sensitive to oxygenate removal via precipitation or to precipitationinduced departures from photochemical equilibrium. These conjectures, plus the paucity of studies of gas/ice interactions during depositional growth, provide further motivation for the study.

[8] We begin with a description of the techniques employed to grow and chemically analyze vapor-deposited ice. Samples were grown in ambient air that was spiked with $\sim 0.01 \mathrm{~Pa}(130 \mathrm{ppbv}$ at Laramie pressure, $780 \mathrm{hPa})$ of gaseous analyte; roughly two orders of magnitude larger than the partial pressures of these compounds in the unpolluted troposphere. No references were found to indicate that bulk phases other than the solid solution can form in our experiments. Next we present results from surface uptake experiments and conclude that volume uptake is dominant for the studied compounds. Also examined are kinetic and thermodynamic dependencies of the derived 


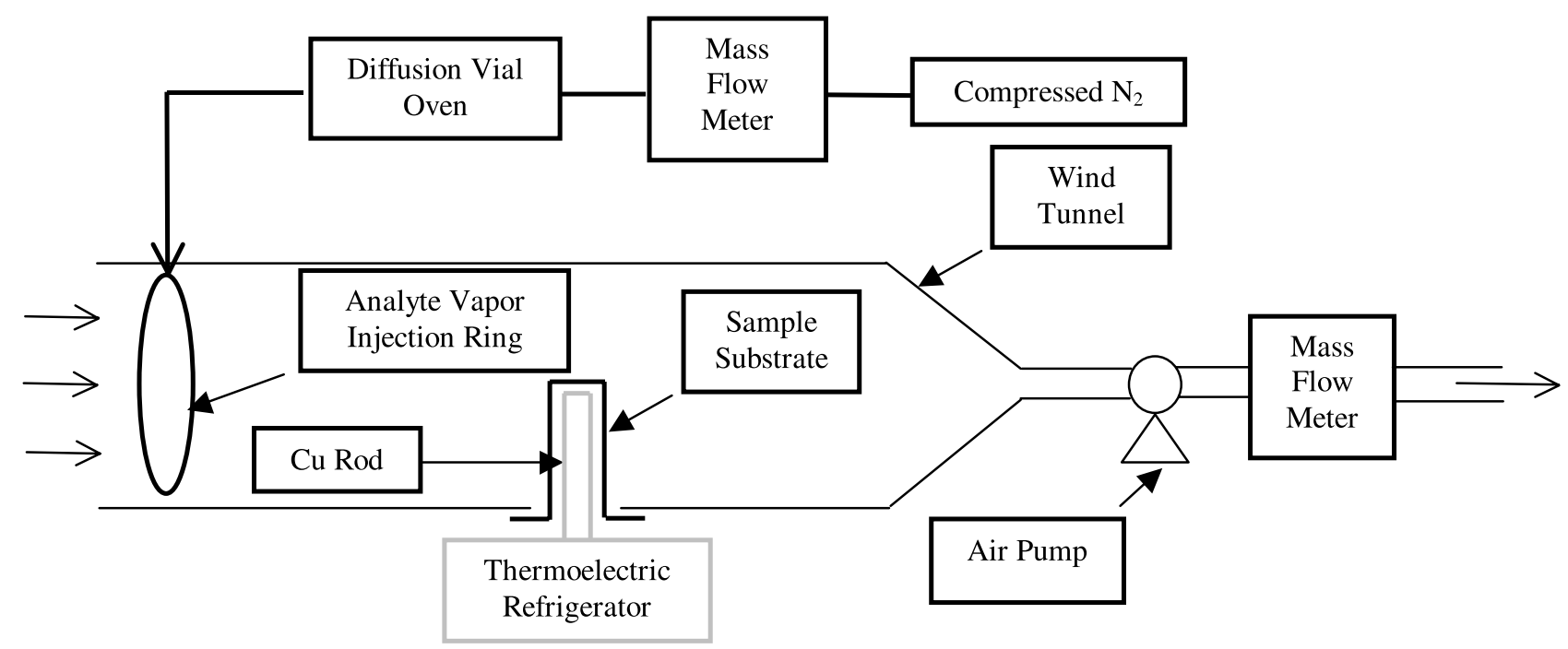

Figure 1. Schematic of ice collection apparatus.

volume uptake coefficients. These results indicate that the volume uptake coefficients are relatively insensitive to the rate of water vapor deposition, suggesting that equilibrium is maintained during our "growing" ice experiments. Lastly, we develop a volume uptake parameterization and show how this approach can be used to describe alkanol/ice interactions occurring in tropospheric clouds.

\section{Measurements}

[9] The gas/solid solution volume uptake coefficients, $K_{g, \mathrm{ss}}\left(\mathrm{mol} \mathrm{m}{ }^{-3} \mathrm{~Pa}^{-1}\right)$, were derived from measurements of ice-bound analyte amount $\left(n_{a}, \mathrm{~mol}\right)$, ice mass $\left(m_{i}, \mathrm{~kg}\right)$ and analyte partial pressure $\left(p_{a}, \mathrm{~Pa}\right)$. These quantities are related by equation (2):

$$
K_{g, \mathrm{ss}}=\rho_{i} \frac{n_{a}}{m_{i} p_{a}}
$$

Here $\rho_{i}$ is the bulk density of ice, which we take to be $916 \mathrm{~kg} \mathrm{~m}^{-3}$. The techniques used to quantify $n_{a}, m_{i}$ and $p_{a}$ are described below.

\subsection{Sampling Site}

[10] Ice samples were collected from January to April 1998 on the roof (20 meters above ground level) of the University of Wyoming Engineering Building, located roughly in the center of Laramie, Wyoming $(2.2 \mathrm{~km}$ above sea level, population 28,000 ). In order to minimize exposure to vehicular emissions and other predominately daytime sources of interfering compounds, and to utilize optimal sampling conditions of low temperature and high relative humidity, sampling was conducted from the windward side of the building, primarily between 2300 and 0600 LT. Ambient relative humidity, expressed relative to water saturation pressure over supercooled liquid water, never exceeded $90 \%$.

\subsection{Ice Sample Collection}

[11] Ice was deposited in the presence of controlled partial pressures of one or more analytes. Gaseous analyte was introduced into

ndrical wind tunnel via an injection ring (Figure 1). The distance from the injection ring to the sample substrate is $1.1 \mathrm{~m}$ and the tunnel diameter is $0.2 \mathrm{~m}$. In a separate series of experiments, $\mathrm{SF}_{6}$ was used as a tracer to verify that uniform mixing occurred between the injection ring and the ice substrate [Huffman, 1999]. Tunnel flow velocities were controlled by the air pump, were derived from measured mass flow rates (assuming incompressible flow) and were varied between 0.2 and $0.5 \mathrm{~m} / \mathrm{s}$. This variability is accounted for in our calculation of $p_{a}$ (section 2.3), but no significant relationship between wind tunnel velocity and analyte uptake was uncovered. Results corresponding to all wind tunnel speeds were therefore pooled for this analysis.

[12] The ice substrate consists of a $6 \mathrm{~mm} \mathrm{OD} \times 100 \mathrm{~mm}$ section of borosilicate glass tubing fitted to a ground glass joint that couples to both the wind tunnel during ice sample collection (Figure 1) and to the sample volatilization chamber during analysis (discussed below). The substrate was cooled by extracting heat with a thermoelectric refrigerator; the refrigerator was attached to a $2 \mathrm{~mm} \mathrm{OD} \times 100 \mathrm{~mm}$ copper rod inserted into the open end of the ice substrate. A thermocouple was placed midway along the length of the copper rod and was used to monitor rod temperature. The rod temperatures were set between $1^{\circ}$ and $9^{\circ} \mathrm{C}$ colder than the ambient frost point temperature. The substrate surface temperature $\left(T_{x}\right)$ was derived using a two-parameter fit which related $T_{x}$, ambient air temperature and rod temperature. For this derivation, a thermocouple was fixed to the outside surface of the sample substrate in order to directly measure $T_{x}$ as a function of air and rod temperature. The thermocouple was removed for the uptake experiments. Departures between direct measurements of $T_{x}$ and predictions of the fit were smaller than $0.7^{\circ} \mathrm{C}$ [Huffman, 1999]. The mass of each ice sample $\left(m_{i}\right)$ was determined gravimetrically and ranged between 18 and $130 \mathrm{mg}$. Error associated with the ice mass measurement is $\pm 5 \mathrm{mg}$. Ambient frost point temperatures were determined from measurements of the ambient ice bulb and air temperatures [List, 1984].

[13] Visual inspection of the ice samples revealed a deposit consisting of faceted crystals which typically grew normal to the cylindrical substrate. Mathematical descrip- 


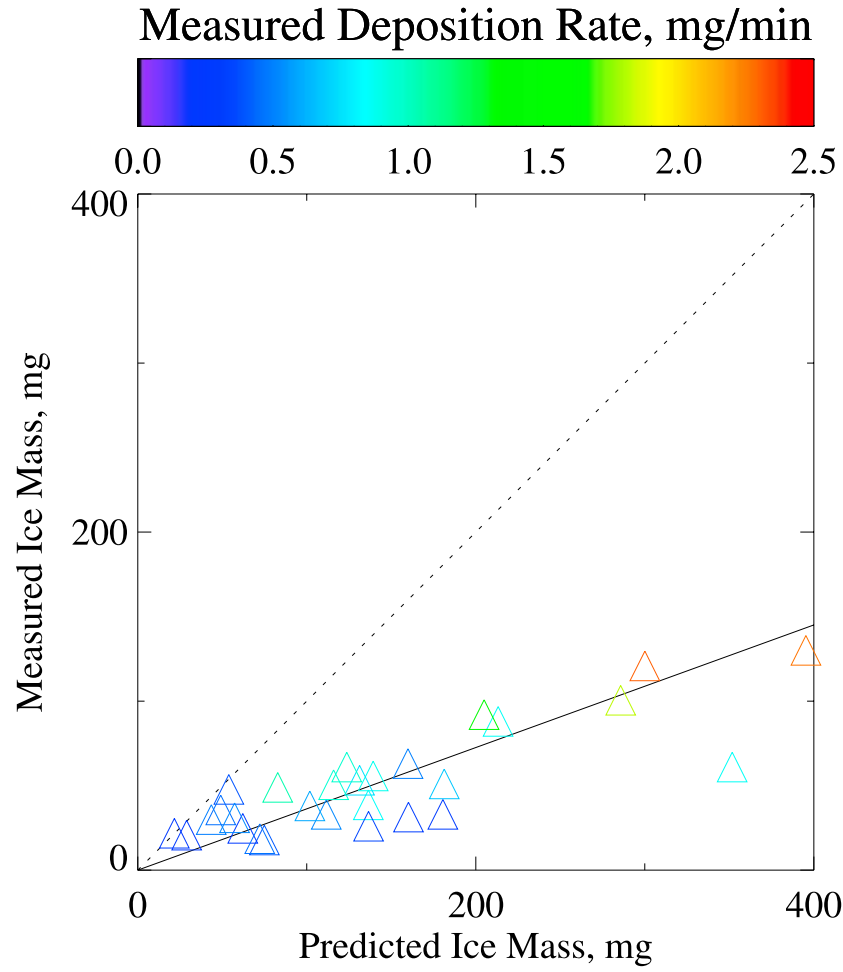

Figure 2. Observed ice mass versus that predicted by equation (3) of Avila et al. [2001]. The solid line is a singleparameter fit of the form $Y=m * X$.

tions of vapor deposition on cylinders are available [e.g., Avila et al., 2001], but these assume that the deposit is smooth and ignore limitations to growth imposed by heat conduction through individual crystals. Figure 2 shows measurements of ice sample mass plotted versus mass predictions based on equation (3) from Avila et al. [2001]. Had our samples not been composed of individual ice crystals that expression would have been expected to reproduce our measurements. Predicted ice masses exceed those measured by approximately a factor of three. Better consistency was obtained for low-mass samples $(<50 \mathrm{mg})$ suggesting that the larger deposits may have lost mass by splintering [Schaeffer and Cheng, 1971]. If splintering occurred, it would not be expected to bias the values of $K_{g, \mathrm{ss}}$ we report. Since we have no direct evidence indicating that splintering did occur, there may be another explanation for the measured-to-predicted ice mass disparity. One plausibility is that measured mass was limited by heat transfer through the enlarging crystals.

[14] Also indicated in Figure 2, by way of the color scale, is the water vapor deposition rate. This was evaluated as the ratio of the ice mass and the sample collection time. Sample collection times were 1-2 hours and larger deposition rates generally imply larger sample mass.

\subsection{Analyte Partial Pressures}

[15] The diffusion vial technique of Altshuller and Cohen [1960] was used to prepare analyte/ $\mathrm{N}_{2}$ gas-phase mixtures. These were fed continuously from a diffusion vial (VICI Metronics Inc., Santa Clara, CA; vial sizes "C" and "D") to the wind tunnel via njection ring. Dilution of the analyte $/ \mathrm{N}_{2}$ mixtures within the wind tunnel reduces the analyte partial pressures by a factor that ranges between 400 and 1000 . The diffusion vials were filled with either pure liquid analyte or mixtures of up to four miscible analytes. Since experiments conducted with one analyte yielded volume uptake coefficients consistent with that obtained from experiments employing as many as four analytes (section 3.1), and the mixture experiments increased the number of data values obtained from a single ice sample, only six out of the 77 volume uptake measurements reported here correspond to single-analyte sample runs.

[16] The vials were installed in an oven whose temperature was regulated to within $\pm 1^{\circ} \mathrm{C}$ (Figure 1). Gaseous analyte mass flux from the vial was predicted using measurements of the temperature of the vial, saturation partial pressure data and the physical dimension of the vial. Analyte diffusivities used in the gaseous analyte flux calculations were based on the same temperature and absolute pressure corrections used for water vapor diffusion in air [Lugg, 1968; List, 1984], and when liquid mixtures were employed, Raoult's law was used to infer the component partial pressures. For pure liquids the predicted flux rates were the same, within errors $( \pm 30 \%$, see below), as those measured gravimetrically. Systematic discrepancies, as large as $50 \%$, were found when the predicted fluxes from liquid mixtures were compared to measured flux rates. The latter were inferred from periodic measurements of the mass and composition of the liquid within the diffusion vial. Composition measurements were obtained by injecting the vial solutions, diluted in water, into the analytical system (section 2.4). These injections were made via the septum injection port described in the following section. Since we assumed Raoult's law was valid, predicted-to-measured flux rate discrepancies might be partially attributable to that assumption. Indeed, the predicted-to-measured flux rate ratio for an acetone/methanol mixture was 0.8 and 0.6 , for methanol and acetone, respectively. Within the errors associated with our technique (see below), these results agree with measured departures from Raoult's law for acetone/ methanol mixtures [Van Ness and Abbott, 1978]. As was already noted, some of the mixtures contained up to four miscible analytes. Thermodynamic data were not found for the three and four component mixtures and to avoid a bias coming from the Raoult's law assumption, or from the calculation of vapor diffusivities, measured flux rates were used to infer the analyte partial pressures $\left(p_{a}\right)$ for all of the mixtures, including the only two-component system (acetone/methanol). On the basis of our comparison of measured and predicted flux rates for pure liquids and the two component liquid mixture, we estimate that the relative magnitude of the uncertainty associated with $p_{a}$ is smaller than $30 \%$. We use $\pm 30 \%$ in our error analysis.

\subsection{Analytical Chemistry}

[17] In this section we present a description of the analytical system used to quantify the molar amount of analyte contained in the ice samples $\left(n_{a}\right)$. A complete description of the system, shown in Figures $3 a$ and $3 b$, and its characterization, can be found in Huffman [1999]. Key components of the analytical system are the gas chromatograph (GC; Hewlett Packard 5890), the flame 


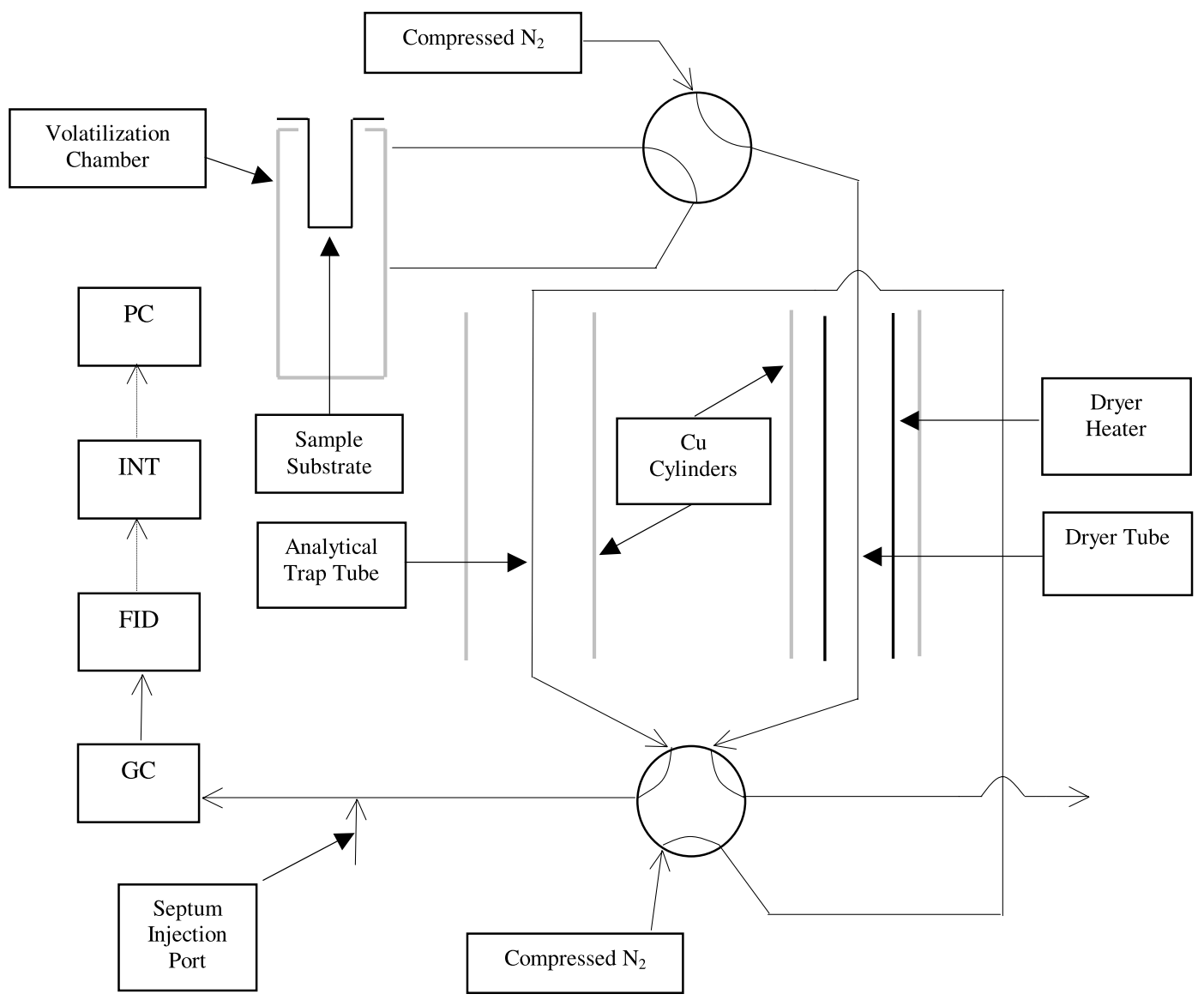

Figure 3a. Schematic of the analytical system configured to volatilize ice samples in the volatilization chamber. This configuration was also used to analyze compounds trapped in the analytical trap and to remove water from the dryer. Thin black lines indicate $\mathrm{N}_{2}$ and $\mathrm{N}_{2}$ /analyte streams. FID, flame ionization detector; GC, gas chromatograph; INT, integrator; PC, personal computer. See text for details.

ionization detector (FID, Hewlett Packard 3235A), the sample volatilization chamber, the ice substrate, the dryer, the analyte trap, and the septum injection port . To minimize analyte loss, flow paths were constructed using borosilicate glass, stainless steel and PFA Teflon. Furthermore, the temperature of the sample lines, and valves, were regulated at $80^{\circ} \mathrm{C}$. Figure $3 \mathrm{a}$ shows the system configured to volatilize ice samples placed in the volatilization chamber. Figure $3 \mathrm{~b}$ shows the system configured to cryogenically trap analyte received from the volatilization chamber.

[18] Water used for the characterization of the analytical system (section 2.6) was purified by distillation followed by passage through Millipore Ion-ex and Organex cartridges. Hereafter we refer to this material as purified water. Purity of the organic compounds exceeded $98 \%$.

[19] The FID was used to detect analytes subsequent to their separation on a gas chromatography column $(30 \mathrm{~m} \times$ $0.53 \mathrm{~mm}$ OD $\times 3 \mu \mathrm{m}$ stationary phase thickness (Supelco VOCOL)). Analyte retention times, defined as the time interval from sample injection to the peak FID response, were used to identify the analytes. Identification was accomplished by producing a library of reference chromatograms corresponding to aqueous mixtures containing either a single compound or a series of compounds having a known retention order. the $\mathrm{GC}$ in the same manner as the ice samples (see section 2.5). The connection between retention times and compound identity was established by comparing retention times recorded in the reference chromatograms to retention times corresponding to the ice sample chromatograms. There was no coelution or peak overlap of the compounds used in this study.

[20] FID calibration factor $\left(f_{c}\right)$ was determined by introducing fixed volumes $(1 \mu \mathrm{L} \sim 0.001 \mathrm{~g})$ of an aqueous standard $(10$ to $2000 \mu \mathrm{M})$ into the GC-FID. These were injected into the GC via a septum injection port (Figure 3). The FID calibration factor is defined as the slope of the line derived from plotting analyte quantity (molar amount) versus the integrated FID response. Relative errors associated with $f_{c}$ are $\pm 5 \%$.

[21] For our $K_{g, \mathrm{ss}}$ measurements, representative values of the ice and analyte masses were $5 \times 10^{-2}$ and $3 \times 10^{-8} \mathrm{~g}$, respectively. As is discussed in section 2.5 this material was vaporized into dry nitrogen before transfer via the flow paths shown in Figure $3 \mathrm{~b}$. To avoid plugging the analyte trap with condensed water the nitrogen/water/analyte mixture was first dried by passing it through a dryer operated at $-30^{\circ} \mathrm{C}$. The dryer tube consists of a $6 \mathrm{~mm}$ OD PFA tube packed with glass wool and surrounded by a cylindrical electrical resistance heater and a copper pipe. 


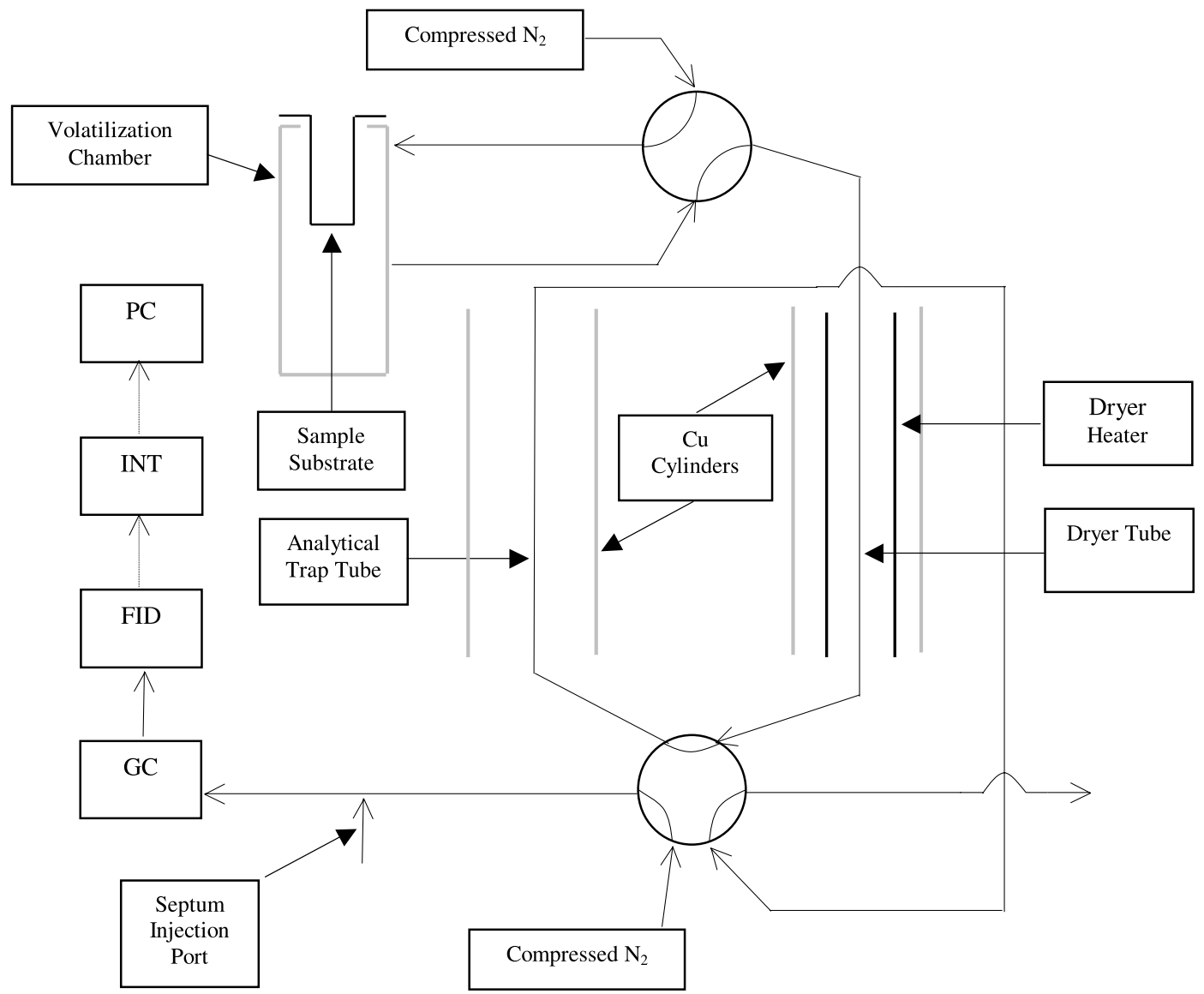

Figure 3b. Schematic of the analytical system configured to cryogenically trap gaseous analyte coming from the volatilization chamber. This configuration was also used to inject aqueous samples via the septum injection port. Thin black lines indicate $\mathrm{N}_{2}$ and $\mathrm{N}_{2}$ /analyte streams. FID, flame ionization detector; G, gas chromatograph; INT, integrator; PC, personal computer. See text for details.

The copper pipe is welded to a fin which is immersed in liquid nitrogen. Neither the fin nor the liquid nitrogen reservoir are shown in Figure 3. The temperature of the dryer tube is controlled by passing current through the electrical resistance heater. The same basic design is used for the analyte trap but there are differences. First, the analyte trap tube $(1.5 \mathrm{~mm}$ OD stainless steel) is narrower than the dryer tube, second the analyte trap tube also functions as an electrical resistance heater, and third the temperature of the analyte trap tube is considerably colder than that of the dryer tube.

[22] Table 1 summarizes the efficiency of analyte transmission through the dryer $\left(f_{t}\right)$. These were evaluated in the following manner: Liquid test solutions composed of a known amount of analyte and $0.1 \mathrm{~g}$ of purified water were placed in the volatilization chamber. These were processed

Table 1. Summary of Measured and Derived Parameters ${ }^{\mathrm{a}}$

\begin{tabular}{|c|c|c|c|c|c|c|c|c|c|}
\hline \multirow[b]{2}{*}{ Compound } & \multirow[b]{2}{*}{$f_{t}$} & \multicolumn{2}{|c|}{$P_{a}, \mathrm{~Pa}$} & \multicolumn{2}{|c|}{$T_{x},{ }^{\circ} \mathrm{C}$} & \multicolumn{2}{|c|}{$T_{f},{ }^{\circ} \mathrm{C}$} & \multirow{2}{*}{$\begin{array}{c}K_{g, s s}^{263}, \\
\mathrm{~mol} \mathrm{~m}^{-3} \mathrm{~Pa}^{-1}\end{array}$} & \multirow{2}{*}{$\begin{array}{c}\Delta H_{g, s s}, \\
\mathrm{~kJ} \mathrm{~mol}^{-}\end{array}$} \\
\hline & & Minimum & Maximum & Minimum & Maximum & Minimum & Maximum & & \\
\hline Methanol & $0.85 \pm 0.02$ & 0.003 & 0.014 & -24 & -9 & -21 & -3 & $3.1 \pm 1.1$ & $37 \pm 33$ \\
\hline Ethanol & $0.66 \pm 0.03$ & 0.001 & 0.004 & -24 & -4 & -21 & -2 & $2.2 \pm 0.7$ & $70 \pm 28$ \\
\hline n-propanol & $0.76 \pm 0.02$ & 0.001 & 0.005 & -24 & -4 & -21 & -1 & $2.9 \pm 0.9$ & $40 \pm 29$ \\
\hline n-butanol & $0.61 \pm 0.08$ & 0.002 & 0.003 & -24 & -4 & -21 & -2 & $1.7 \pm 0.6$ & $40 \pm 39$ \\
\hline tert-butanol & $0.44 \pm 0.02$ & 0.012 & 0.016 & -12 & -10 & -8 & -8 & $5.2 \pm 1.7$ & na \\
\hline Cyclohexanol & $0.02 \pm 0.02$ & 0.002 & 0.002 & -8 & -7 & -1 & 0 & $3.3 \pm 3.6$ & na \\
\hline Acetone & $0.82 \pm 0.11$ & 0.010 & 0.016 & -13 & -8 & -10 & -5 & $0.85 \pm 0.46$ & na \\
\hline Toluene & $0.62 \pm 0.15$ & 0.012 & 0.012 & -12 & -10 & -8 & -7 & $0.012 \pm 0.005$ & na \\
\hline
\end{tabular}

${ }^{\mathrm{a}} f_{t}$, transmission efficiency of the analytical system; $P_{a}$, analyte partial pressure; $T_{x}$, substrate temperature; $T_{f}$, ambient frost point temperature; $K_{g, s s}^{263}$, volume uptake coefficient evaluated at $-10^{\circ} \mathrm{C} ; \Delta H_{g, s s}$, vapor-to-solid solution enthalpy; na, not available. In the case of methanol, ethanol, n-propanol, and n-butanol, $K_{g, s s}^{263}$ is derived by evaluating the Van't Hoff function at $-10^{\circ} \mathrm{C}$. For the other compounds, $K_{g, s s}^{263}$ is the mean of all measurements. Uncertainty in $f_{t}$ is expressed as plus or minus one standard deviation of the mean of four measurements. The uncertainty shown for $K_{g, s s}^{263}$ is calculated by propagating error from uncertainty in $m_{i}, n_{a}$, an he uncertainty in $\Delta H_{g, s s}$ represents statistical error in the slope value derived from the Van't Hoff fit. 
in the same manner as the ice samples (section 2.5). Values of transmission efficiency were computed by comparing the FID response to a reference FID response corresponding to an aqueous standard injected via the septum injection port (Figure 3). The standards contained the same analyte mass as the test solutions but the former were composed of $0.001 \mathrm{~g}$ water (solution volume $1 \mu \mathrm{L}$ ). With one exception (cyclohexanol), the transmission efficiencies are larger than 0.4. Also with the exception of cyclohexanol, the absolute magnitude of the relative error associated with $f_{t}$ is smaller than $20 \%$.

[23] Analyte amount in the ice samples was derived using equation (3):

$$
n_{a}=\frac{\mathrm{A} f_{c}}{f_{t}} .
$$

In equation (3), A represents the peak-area-integrated FID response to a processed ice sample.

\subsection{Ice Sample Processing}

[24] After collection the ice samples were weighed in a cold room and transferred to the volatilization chamber (located in an adjacent laboratory). The samples remained solid during the cold room to laboratory transfer. Sample processing is an eight-step procedure: (1) the analytical system is configured as shown in Figure 3a, (2) the volatilization chamber is heated to $120^{\circ} \mathrm{C}$, (3) the volatilization chamber is configured as shown in Figure $3 b,(4)$ the $\mathrm{H}_{2} \mathrm{O}$ /analyte/ $\mathrm{N}_{2}$ mixture is passed at $140 \mathrm{~cm}^{3} / \mathrm{min}$ through the dryer $\left(-30^{\circ} \mathrm{C}\right)$ and cryofocussed on the analyte trap $\left(-140^{\circ} \mathrm{C}\right),(5)$ the nitrogen flow through the dryer and trap is stopped, (6) the analyte trap is rapidly (in about $5 \mathrm{~s}$ ) heated to $90^{\circ} \mathrm{C},(7)$ the system is configured as shown in Figure $3 \mathrm{a}$; this configuration delivers trapped analyte to the GC-FID and also removes condensed water and any remaining analyte from the dryer, readying it for the next sample, and (8) the column temperature is ramped from $30^{\circ}$ to $54^{\circ} \mathrm{C}$ at $3^{\circ} \mathrm{C} / \mathrm{min}$, from $54^{\circ}$ to $220^{\circ} \mathrm{C}$ at $10^{\circ} \mathrm{C} / \mathrm{min}$ and held at $220^{\circ} \mathrm{C}$ for $2 \mathrm{~min}$. Owing to the temperature dependence of gas viscosity, the carrier gas flow rate during steps 7 and 8 varies from 4 to $6 \mathrm{~cm}^{3} / \mathrm{min}$. The FID signal is recorded at $5 \mathrm{~Hz}$ on a Hewlett Packard 3396 integrator (INT in Figure 3) and analyzed on a personal computer using the Hewlett Packard Chemstation software package.

\subsection{Analytical System Characterization}

[25] Results from three analytical system characterization studies established the minimum detectable analyte amounts in ice and analyte amounts attributable to contamination and surface uptake. In the first set of experiments ice samples were grown in air that was not enriched with analyte vapor. From these studies (nine samples) we estimate that the detection limits for compounds other than methanol and acetone are approximately $10 \mathrm{pmol}$. The detection limit was taken to be two times the standard deviation of the $n_{a}$ values obtained from these "ice blank" experiments. Analyte amounts for methanol and acetone in these "ice blank" experiments were $\sim 100$ pmol suggesting that partial pressures in the ambient air were $\sim 0.001 \mathrm{~Pa}$, or that partial pressures in our laboratory air were $\sim 0.01 \mathrm{~Pa}$. The former hypothesis is consistent with methanol and acetone incorporation into the "ice ' during vapor deposition and the latter is consistent with contamination coming from the air in our laboratory. If the latter was true we expected to observe methanol and acetone when processing purified water samples.

[26] In a second set of characterization experiments we attempted to quantify the eight analytes in $0.1 \mathrm{~g}$ samples of purified water. Values of $n_{a}$ from these studies were $70 \pm$ $10 \mathrm{pmol}(n=5)$ and $150 \pm 50 \mathrm{pmol}(n=5)$ for methanol and acetone, respectively. For the six other compounds (ethanol, n-propanol, n-butanol, tert-butanol, cyclohexanol and toluene) the values of $n_{a}$ observed in these "water blank" experiments were not larger than the detection limit (10 pmol). Thus methanol and acetone detected during either the "water blank" or the "ice blank" characterizations are consistent with the lab air contamination hypothesis. We conjecture that the lab air entered the volatilization chamber when it was opened to introduce these samples. Since ice sample processing involves opening the volatilization chamber, the blank values represent a bias. This was accounted for by subtracting 70 pmol and 150 pmol from the values of $n_{a}$ for methanol and acetone, respectively. For methanol and acetone this blank correction augments other errors associated with the determination of $n_{a}$ (section 2.4) and we estimate this error to 100 pmol. This uncertainty is accounted for in our error analysis. Detection limit values for methanol and acetone were estimated to be $100 \mathrm{pmol}$.

[27] In a third set of characterization experiments we prepared ice samples without any added analyte and subsequently exposed these samples to $0.06 \mathrm{~Pa}$ of each of the $\mathrm{C}_{1}-\mathrm{C}_{4}$ normal alkanols for 1 hour. These ice samples were not cooled subsequent to exposure to gaseous analytes, so the detected amounts are thought to be confined to the iceair interface. Two of these experiments were conducted, both at $-9^{\circ} \mathrm{C}$. Analyte amounts in these two samples, blank corrected in the case of methanol, were at or below the detection limits. Given this information, and the sample masses (0.07 and $0.04 \mathrm{~g})$, the analyte contribution attributable to surface uptake was estimated. Our approach is to calculate an effective volume uptake coefficient, assuming that $n_{a}$ was equal to the detection limit values discussed in the previous paragraph. The upper limit effective volume uptake coefficients, based on the $0.04 \mathrm{~g}$ ice sample and a partial pressure of $0.06 \mathrm{~Pa}$, are $0.04 \mathrm{~mol} \mathrm{~m}^{-3} \mathrm{~Pa}^{-1}$ for methanol and $0.004 \mathrm{~mol} \mathrm{~m}^{-3} \mathrm{~Pa}^{-1}$ for ethanol, n-propanol and n-butanol. The volume uptake coefficient values we report for the $C_{1}$ to $C_{4}$ normal alkanols (Table 1) are approximately one hundred times larger than the effective volume uptake coefficients. These experiments indicate that volume uptake is the dominant process, but do not exclude the possibility that surface-bound analytes were lost from samples during transfer from the wind tunnel (sample collection), to the cold room (sample weighing) and to the laboratory (sample analysis). We did not conduct surface uptake studies for acetone, tert-butanol, cyclohexanol or toluene, and assume that surface uptake is also negligible for those analytes based on the results discussed above.

\subsection{Analytical Uncertainties}

[28] The next to the last column of Table 1 reports the volume uptake coefficients at $-10^{\circ} \mathrm{C}\left(K_{g, \mathrm{ss}}^{263}\right)$, and uncertainties. In addition to the methanol and acetone uncertainties discussed in section 2.6, uncertainties in the reported values 
Table 2. Pearson Product Moments and Yes/No Indication of Significant Correlations ${ }^{\mathrm{a}}$

\begin{tabular}{lccccccc}
\hline Analyte & $n$ & $K_{g, s s}$ Versus $T_{d p}-T_{x}$ & $K_{g, s s}$ Versus Deposition Rate & Deposition Rate Versus $T_{x}$ & $K_{g, s s}$ Versus $T_{x}$ & $\ln K_{g, s s}$ Versus $T_{x}^{-1}$ \\
\hline Methanol & 13 & +0.2 (no) & +0.2 (no) & +0.4 (no) & +0.4 (no) & -0.6 (yes) \\
Ethanol & 15 & +0.5 (no) & +0.3 (no) & +0.3 (no) & +0.8 (yes) & -0.8 (yes) \\
n-propanol & 13 & +0.5 (no) & +0.5 (no) & +0.4 (no) & +0.6 (yes) & -0.7 (yes) \\
n-butanol & 15 & +0.6 (yes) & +0.4 (no) & +0.2 (no) & +0.5 (no) & -0.5 (no) \\
\hline
\end{tabular}

${ }^{\text {a }}$ Significance was tested using the $t$ distribution at the 0.05 level of significance. $n$, number of data points; $T_{d p}$, ambient dew point temperature; $T_{x}$, substrate temperature; $K_{g, s s}$, volume uptake coefficient.

of $K_{g, \mathrm{ss}}^{263}$ include errors associated with the transmission efficiency ( $3 \%$ to $100 \%$ relative error; Table 1$)$, the ice mass measurement $( \pm 5 \mathrm{mg}$; section 2.2$)$, the GC-FID calibration ( $\pm 5 \%$ relative error; section 2.4$)$, and the analyte partial pressure $( \pm 30 \%$ relative error; section 2.3$)$.

\section{Results}

[29] The measurements of $K_{g, s s}$ were made as functions of ambient temperature, ambient frost point temperature, substrate temperature, and analyte partial pressure. Both substrate temperature and analyte partial pressure were held constant during the sample runs. Ambient temperature and ambient frost point temperature varied over the course of some of the sample runs, but since the samples were collected late at night (section 2.1) that variation was less than $2^{\circ} \mathrm{C}$. Minimum and maximum values of analyte partial pressure $\left(P_{a}\right)$, substrate temperature $\left(T_{x}\right)$ and ambient frost point temperature $\left(T_{f}\right)$ are presented in Table 1 . The substrate temperature was $1^{\circ}-9^{\circ} \mathrm{C}$ colder than the ambient frost point temperature. For nearly all samples the substrate temperature was colder than the ambient dew point temperature, but never by more than $8^{\circ} \mathrm{C}$. This implies that the liquid water could have condensed, but this inference is inconsistent with the observations discussed in section 2.2.

[30] Some of the possible correlations between $K_{g, \mathrm{ss}}$, humidity and substrate temperature are reported in Table 2. The number of measurements is shown in the second column. Note that correlations are only meaningful for the $\mathrm{C}_{1}-\mathrm{C}_{4}$ normal alkanols because fewer measurements are available for tert-butanol $(n=4)$, cyclohexanol $(n=3)$, toluene $(n=5)$ and acetone $(n=9)$ and since data for these compounds are restricted to a narrower range of substrate temperature $\left(-7\right.$ to $\left.-13^{\circ} \mathrm{C}\right)$.

[31] Valdez et al. [1989] showed that $\mathrm{SO}_{2}$ volume uptake was reduced by a factor of two when the substrate was cooled to the ambient dew point temperature. They conjectured that this resulted from diffusional loss of dissolved $\mathrm{SO}_{2}$ from condensed or impacted liquid water. The third column of Table 2 shows just the opposite to be the case for our data set; that is, we find a weak but positive correlation between $K_{g, s s}$ and the difference between dew point temperature $\left(T_{\mathrm{dp}}\right)$ and substrate temperature.

[32] We also investigated a plausible link between $K_{g \text {,ss }}$ and water vapor deposition rate. The fourth column of Table 2 shows that $K_{g, \text { ss }}$ and deposition rate are positively correlated, although the regression coefficients are not significant. While we cannot rule out the possibility that this correlation is indicative of a mechanistic link, we also note that deposition rate and substrate temperature (fifth column) and $K_{g, s s}$ and substrate temperature (sixth column) are also positively correlated. The deposition rate versus $T_{x}$ correlation implies that

ely warm samples were asso- ciated with disproportionately warmer frost point temperatures, compared to the colder samples. In the next section we attempt to untangle the $K_{g, s s}$ versus deposition rate and the $K_{g, s s}$ versus substrate temperature dependences.

[33] Before proceeding, note the significant correlations shown in the final column of Table 2. This implies that the volume uptake coefficients conform to a function of the form

$$
\ln K_{g, \mathrm{ss}}=a / T+b,
$$

where $a$ and $b$ are fitted coefficients. We will refer to this equation as the Van't Hoff fitting function.

\subsection{Sensitivity to Temperature and Water Vapor Deposition Rate}

[34] Figure 4 shows the volume uptake coefficient plotted versus substrate temperature and the Van't Hoff fitting functions for the $\mathrm{C}_{1}-\mathrm{C}_{4}$ normal alkanols. As in Figure 2 the data points are color coded by water vapor deposition rate. The uncertainties were calculated using the measurement errors discussed in sections 2.6 and 2.7 and an error propagation equation based on equations (2) and (3). The six samples (section 2.3) corresponding to single-analyte experiments are shown as squares in the ethanol and n-butanol panels. Since these six do not plot outside the range of the other data values we are fairly confident that multianalyte uptake is comparable to single-analyte uptake. Also note that there is a tendency for high growth rate data values $(>1 \mathrm{mg} / \mathrm{min}$ ) to plot above the Van't Hoff fit. However, we also note that Van't Hoff fits constructed using only samples with water vapor deposition rates smaller than $1 \mathrm{mg} / \mathrm{min}$ are not substantially different from those obtained using all of the data points (results not shown). Indeed, if there is sensitivity to water vapor deposition rate it is masked by the fact that small deposition rate samples $(<1 \mathrm{mg} / \mathrm{min})$ are more numerous than the large deposition rate samples and the fact that the small deposition rate samples are scattered over the whole temperature range. The relative insensitivity to deposition rate and the statistical significance of the $\ln K_{g, \mathrm{ss}} / T_{x}{ }^{-1}$ correlation (Table 2) both suggest that substrate temperature is an important determinant of $K_{g, \mathrm{ss}}$. These results are indicative of a process controlled by equilibria established between analyte and $\mathrm{H}_{2} \mathrm{O}$, and not by their rates of transport. Two inferences support of that conclusion:

[35] 1 . If $K_{g, \text { ss }}$ was controlled by transport, and if analyte transport was limited by accommodation at the ice-air interface as described by alkanol accommodation on supercooled water surfaces [Jayne et al., 1991], an inverse $K_{g, \mathrm{ss}}$ / $T_{x}$ relationship would be expected. The observation of positively correlated values of $K_{g, \text { ss }}$ and $T_{x}$ (Figure 4) contradicts that expectation. 


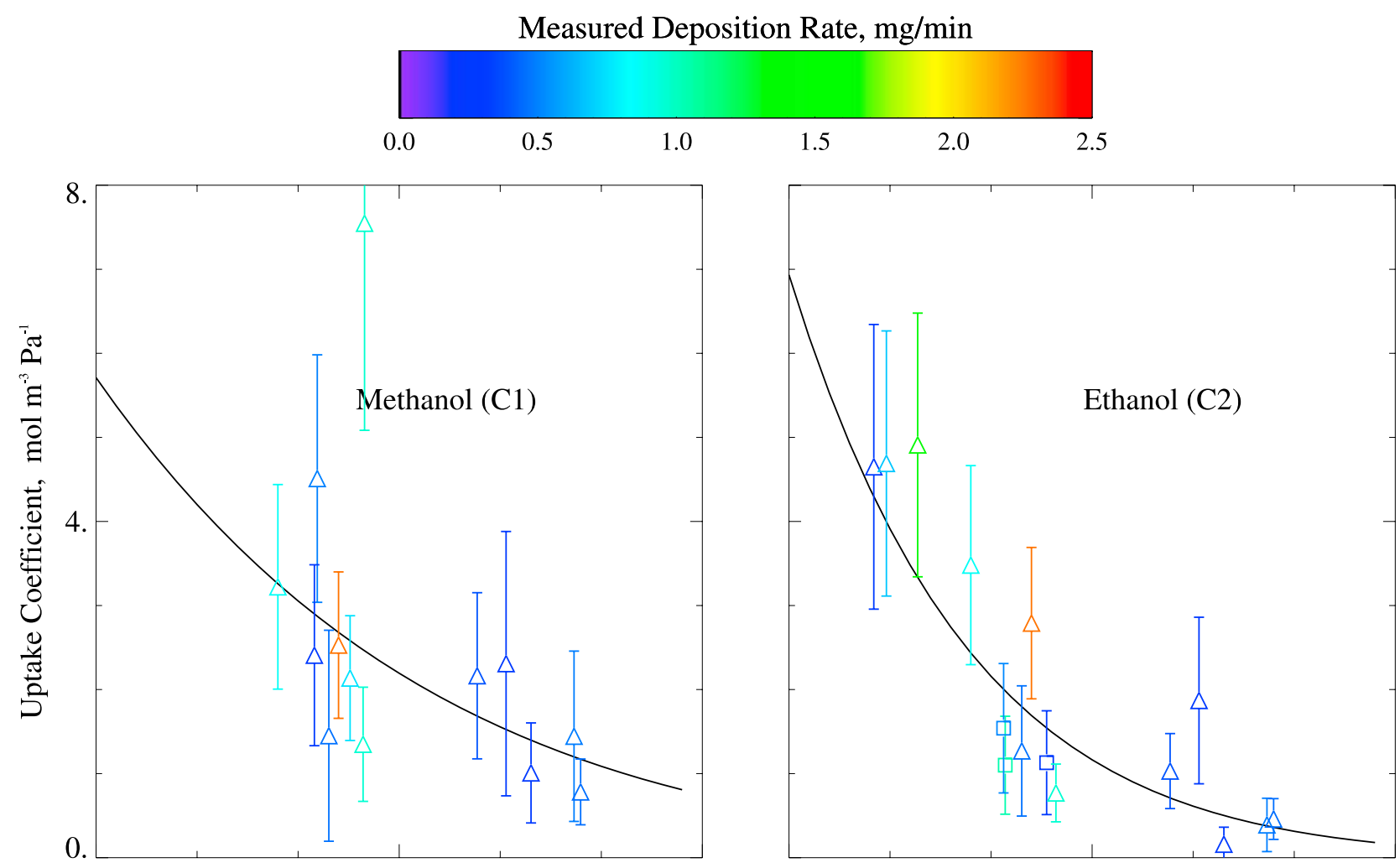

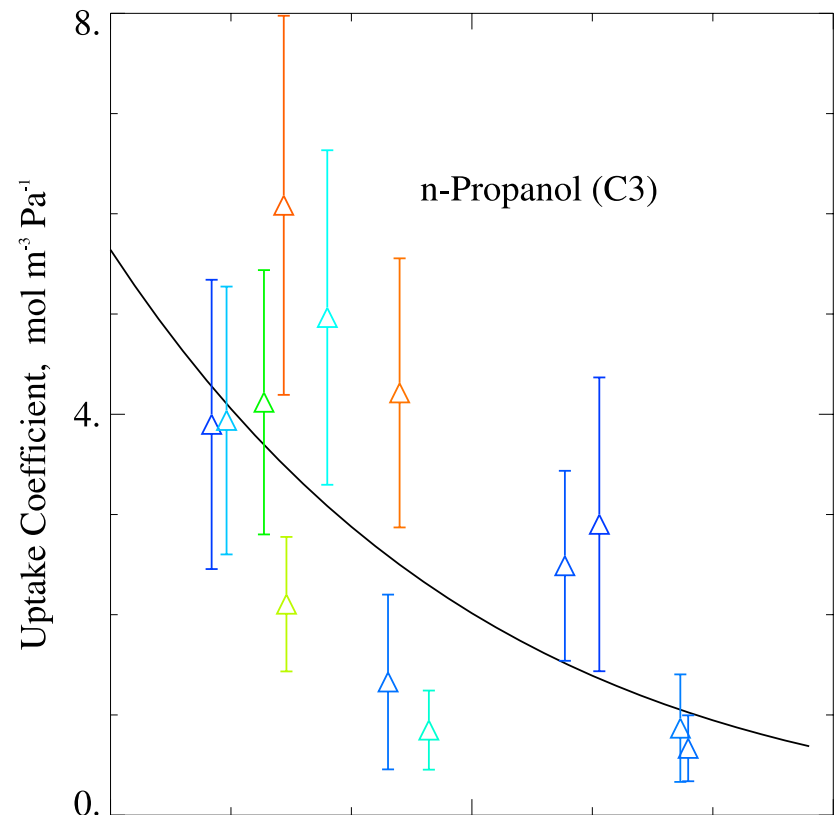

0 . -15 . Substrate Temperature, ${ }^{\circ} \mathrm{C}$

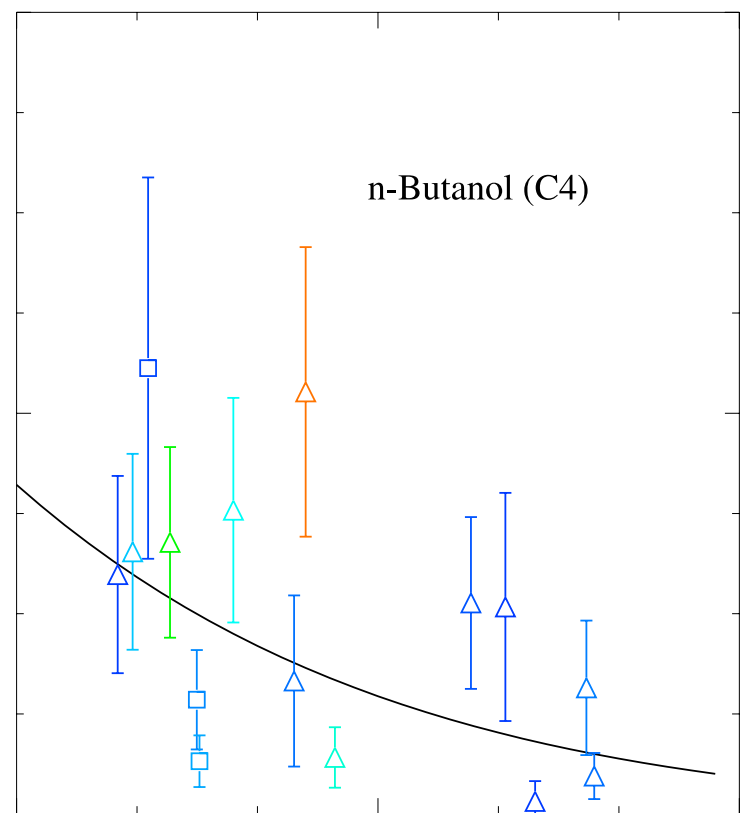

0 .
$-30$.

Substrate Temperature, ${ }^{\circ} \mathrm{C}$

Figure 4. Volume uptake coefficients for the $C_{1}-C_{4}$ normal alkanols. The curve is the Van't Hoff fitting function. Uncertainties were calculated using the measurement errors discussed in sections 2.6 and 2.7 and an error propagation equation based on equations (2) and (3). Single-analyte and multianalyte experiments are indicated by squares and triangles, respectively. 
[36] 2. Table 1 shows that the value of $K_{g, s s}^{263}$ for npropanol is comparable to that for methanol and ethanol. The absence of a clear ranking of the $K_{g \text {,ss }}^{263}$ values for these three compounds contradicts the ranking of accommodation coefficient values for these same compounds as reported by Jayne et al. [1991]. Both the first and the second inference rely on the assumption that the water surface accommodation coefficients reported by Jayne et al. [1991] are relevant to ice surfaces, and based on that assumption they argue against a mechanistic link to the kinetics of gaseous analyte accommodation at the ice-air interface. However, that conclusion does not exclude the possibility of kinetic control resulting from transport phenomena occurring in either the gas or solid phases.

[37] In the absence of evidence to the contrary we now interpret measurements of $K_{g, s s}$ using equilibrium thermodynamics. In this context the coefficient " $b$ " in the Van't Hoff fitting function (equation (4)) is equal to the gas-tosolid solution reaction entropy, divided by the universal gas constant. The relative statistical error associated with the reaction entropy ranges between 50 and $100 \%$. This variability reflects the data scatter shown in Figure 4. The coefficient "a" in equation (4) is equal to the gas-to-solid solution reaction enthalpy, defined as $\Delta H_{g, \mathrm{ss}}$, divided by the universal gas constant. Values of $\Delta H_{g, s s}$, and their statistical error, are presented in the last column of Table 1. We caution that our assignment of coefficient "a" to $\Delta H_{g, \mathrm{ss}} / R$ is inappropriate if bonding to the ice-air interface or uptake into a surface liquid layer are dominating processes. The surface bonding hypothesis is inconsistent with the minimal values of $K_{g, \mathrm{ss}}$ observed when net water vapor deposition was not occurring (section 2.6) and with the exothermicity of surface uptake by ice [Hudson et al., 2002; Sokolov and Abbatt, 2002] and liquid water [Goss, 1994]. The surface liquid layer hypothesis is consistent with the temperature dependence of liquid solution volume reported by Conklin and Bales [1993], but is inconsistent with the exothermicity of alkanol dissolution in liquid water. The temperature dependence of the hypothesized pathways is compared to the observed temperature dependence of $K_{g, \text { ss }}$ in section 4 .

[38] Before discussing the enthalpy values we need to define our standard state. In the standard state the alkanols are assumed to behave as ideal gases. This assumption is consistent with the low partial pressures we employed ( $\sim 0.01 \mathrm{~Pa})$. A second component of the standard state is assumed to be pure ice, so the only type of bonding allowed in the standard state are the water-water bonds in ice. Reaction enthalpies (Table 1) thus have contributions from two different types of bonding occurring in the solid solution: (1) analyte-to-water bonding and (2) water-towater bonding. Since the former interaction is expected for the solid solution, and is presumably exothermic, positive values of $\Delta H_{g, \text { ss }}$ are suggestive of decreased water-water bonding associated with solid solution formation. Evidence in support of this inference comes from parameters derived by fitting our $\mathrm{C}_{1}-\mathrm{C}_{4}$ normal alkanol data to a thermodynamic model based on the Gibbs-Duhem equation for a system consisting of gaseous analyte, water vapor and analyte $/ \mathrm{H}_{2} \mathrm{O}$ solid solution [Hanson and Mauersberger, 1988]. That analysis yielded gas-to-solid solution enthalpies between +34 and $+40 \mathrm{~kJ} / \mathrm{mol}$ and ice saturation vapor depres estimate that relative error associated with the derived ice saturation vapor depression factors is no larger than $10 \%$. Since these factors are less than unity, and therefore smaller than that expected for a nonelectrolytic solute, they suggest that ice saturation vapor pressure over the solid solutions is larger than that anticipated for the ideal case of the solvent (ice) conforming to Raoult's law. This result is consistent with our conjecture that water-water bonding is disrupted by the presence of alkanols.

[39] The endothermicity shown in Figure 4 is suggestive of the thermochemistry of hydrogen bond defect formation in ice [Fletcher, 1970]. In that case, and for the volume uptake coefficients we report, the observed temperature dependence is opposite that anticipated for equilibrium established between solute in the gas and aqueous phases, described by Henry's law. As we discuss in section 4, this temperature dependence has implications for trace gas scavenging that occurs within clouds colder than $0^{\circ} \mathrm{C}$.

[40] Table 1 shows that uptake experiments for analytes other than the $\mathrm{C}_{1}-\mathrm{C}_{4}$ normal alkanols were conducted at substrate temperatures between $-7^{\circ}$ and $-13^{\circ} \mathrm{C}$. On the assumption that the correction from the experimental temperatures to $-10^{\circ} \mathrm{C}$ is small, we report (Table 1) the volume uptake coefficients for tert-butanol, cyclohexanol, acetone and toluene as if they were measured at $-10^{\circ} \mathrm{C}$.

\subsection{Volume Uptake Versus Heat of Vaporization}

[41] Values of $K_{g, \mathrm{ss}}$ at $-10^{\circ} \mathrm{C}\left(K_{g, \mathrm{ss}}^{263}\right)$ for the $\mathrm{C}_{1}-\mathrm{C}_{4}$ normal alcohols and tert-butanol were regressed with several physicochemical properties. Correlates included the enthalpy of fusion, entropy of fusion, enthalpy of vaporization $\left(\Delta H_{\mathrm{vap}}^{298}\right)$ (all from Stull et al. [1969]), saturation partial pressure [Stephenson and Malanowski, 1987], and the Van der Waals volume [Kamlet et al., 1988]. These five are properties of the pure alkanols. We also correlated $K_{g \text {,ss }}^{263}$ with Henry's law coefficients obtained from Snider and Dawson [1985]. The most significant correlation was found for the $K_{g, \mathrm{ss}}^{263} / \Delta H_{\mathrm{vap}}^{298}$ interaction $\left(n=5, r^{2}=0.7\right.$ and $r=-0.8$ ).

[42] Values of $K_{g, \text { ss }}^{263}$ are plotted versus $\Delta H_{\text {vap }}^{298}$ in Figure 5. The uncertainties were calculated using the measurement errors summarized in section 2.7 and an error propagation equation based on equations (2) and (3). Values of $K_{g, s s}^{263}$ for the $\mathrm{C}_{1}-\mathrm{C}_{4}$ normal alcohols and tert-butanol are fitted to a functional form discussed in the following section. We omitted cyclohexanol from the fit because of the large uncertainties in the cyclohexanol transmission efficiency (Table 1) and because the relatively small cyclohexanol transmission efficiency implies a large correction when going from FID peak area to the analyte amount in ice (equation (3)). In spite of this uncertainty, error bounds on $K_{g, \text { ss }}^{263}$ for cyclohexanol imply that the true value could be consistent with the $K_{g, \mathrm{ss}}^{263} / \Delta H_{\mathrm{vap}}^{298}$ trend seen for the other alkanols. The fact that the volume uptake coefficient for cyclohexanol is larger than that for toluene, and comparable to that for the $\mathrm{C}_{1}-\mathrm{C}_{4}$ alkanols, suggests that molecular size is not the main determinant of volume uptake. Larger Van der Waals volume for tert-butanol, compared to the $\mathrm{C}_{1}-\mathrm{C}_{3}$ normal alkanols [Kamlet et al., 1988], and the fact that tert-butanol is characterized by the largest $K_{g, \mathrm{ss}}^{263}$ collaborates this assertion. For the eight analytes we tested, Figure 5 shows that the ability to form hydrogen bonds 


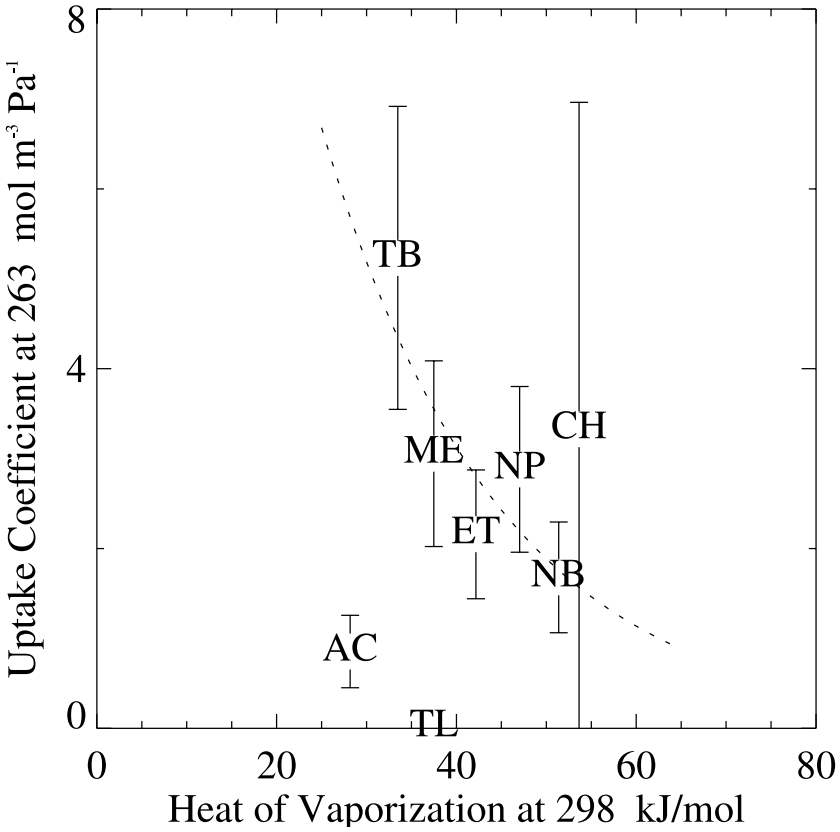

Figure 5. Scatterplot of the volume uptake coefficient, at $263 \mathrm{~K}$, versus the heat of vaporization. The fitting function (dashed line) is based on $\mathrm{C}_{1}-\mathrm{C}_{4}$ normal alkanol and tertbutanol data only. The best-fit line was computed as $K_{g, s S}^{263}=\exp \left[-\left(c_{1}+c_{2} \Delta H_{\mathrm{vap}}^{298}\right) /\left(R T_{i}\right)\right]$, where $c_{1}=-6.9 \times$ $10^{3} \pm 5.4 \times 10^{3} \mathrm{~J} / \mathrm{mol}, c_{2}=0.11 \pm 0.12$, and $T_{i}$ is the reference temperature $(263 \mathrm{~K})$. Plotted uncertainties were calculated using the measurement errors discussed in sections 2.6 and 2.7 and an error propagation equation based on (equations 2) and (3). ME, methanol; ET, ethanol; $\mathrm{NP}$, n-propanol; NB, n-butanol; $\mathrm{CH}$, cyclohexanol; $\mathrm{AC}$, acetone; TL, toluene.

is a factor distinguishing between the relatively large $K_{g, s s}^{263}$ values for the alkanols $\left(\sim 3 \mathrm{~mol} \mathrm{~m}^{-3} \mathrm{~Pa}^{-1}\right)$ and the smaller values $\left(<1 \mathrm{~mol} \mathrm{~m}^{-3} \mathrm{~Pa}^{-1}\right)$ documented for acetone and toluene. Note that acetone, and to lesser extent toluene, are capable of forming hydrogen bonds, as an acceptor; however, neither one of these compounds is an efficient hydrogen bond donor [Kamlet et al., 1988]. The reduction in hydrogen bond forming possibilities for acetone and toluene is consistent with the smaller volume uptake coefficients derived for these two compounds.

\subsection{Parameterization of the Volume Uptake Coefficient}

[43] In this section we develop a thermodynamic explanation for the $K_{g, \mathrm{ss}}^{263} / \Delta \mathrm{H}_{\mathrm{vap}}^{298}$ correlation shown in Figure 5. In Figure 6 consider the gas/liquid and gas/solid saturation pressure curves for methanol (indicated by the gray and black curves). Also illustrated is a process path indicated by vertical and horizontal lines. The path originates from a state where methanol is gaseous $\left(T_{i}=263 \mathrm{~K}\right.$ and $P_{i}=$ $0.01 \mathrm{~Pa}$ ) and proceeds to a state where methanol exists in a solid solution with water ice. The complete transformation is envisioned to occur via the following subprocesses: a) isobaric heat removal from gaseous methanol, b) methanol deposition at the gas/solid coexistence temperature $\left(T_{\text {sat }}\right)$ corresponding to $)$ melting of solid methanol, d) isobaric warming of liquid methanol, superheating it to $T_{i}$, e) mixing of liquid methanol with liquid water in proportions dictated by $K_{g, s s}^{263}$ and the methanol partial pressure, and f) solidification leading to the formation of the methanol/ice solid solution. When viewing Figure 6, note that the temperature scale is too magnified to show subprocesses "e" and "f" or the warmer portions of subprocesses "a" and "d."

[44] Gibbs free energy changes for subprocesses "a," "c," "d," "e," and "f" are evaluated in Table 3. Here we describe the equations used to formulate the Gibbs energies, following the order $\Delta G_{c}, \Delta G_{e}, \Delta G_{f}, \Delta G_{b}, \Delta G_{a}$ and $\Delta G_{d}$.

[45] $\Delta G_{c}$ was evaluated as

$$
\Delta G_{c}=\Delta H_{\text {fus }} \cdot\left(1-T_{\text {sat }} / T_{\text {tp }}\right),
$$

where $T_{\text {sat }}$ is the gas/solid coexistence temperature (Figure 6), $T_{\text {tp }}$ is the triple point temperature and $\Delta H_{\text {fus }}$ is the absolute value of the latent heat of fusion. The values of $\Delta G_{c}$ were calculated using $T_{\text {sat }}$ derived from saturation pressure formulae presented by Stephenson and Malanowski [1987] and using values of $T_{\text {tp }}$ and $\Delta H_{\text {fus }}$ from Stull et al. [1969]. Equation (5) can be derived from Maxwell equations describing the relationship between Gibbs free energy and saturation pressure along the gas/solid and gas/liquid phase boundaries. For ethanol, n-propanol and n-butanol $T_{\text {sat }}$ is greater than $T_{\text {tp }}$ so the gas/solid phase boundary was extrapolated. For evaluating $\Delta G_{e}$ we inferred mixture mole fractions ( $X_{1}$ and $X_{2}$ for water and analyte, respectively)

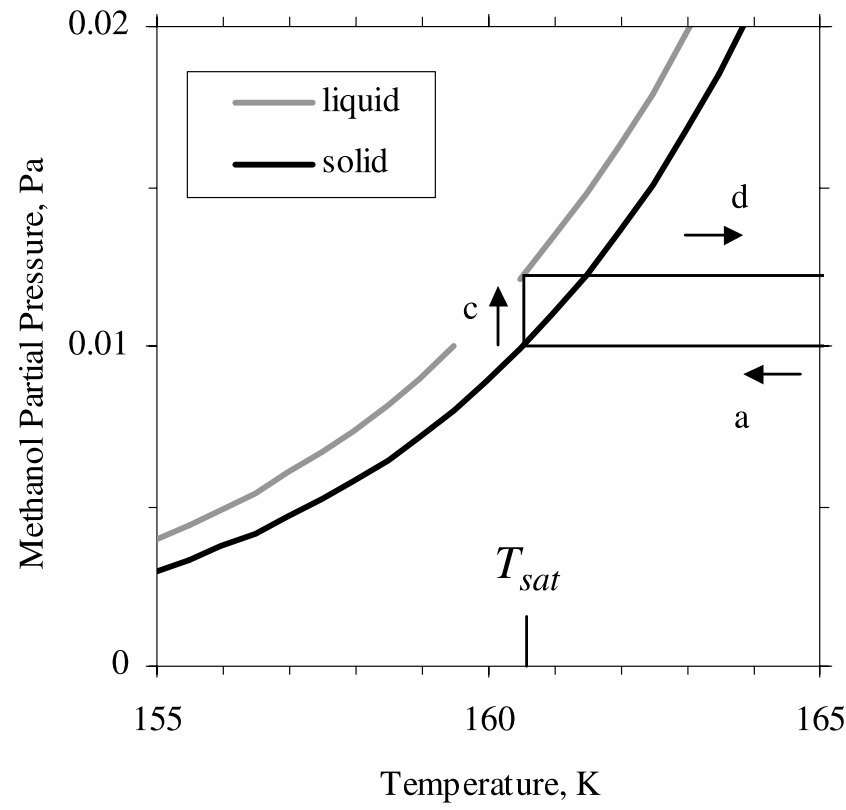

Figure 6. Vapor pressure/temperature diagram for methanol. Note that temperatures plotted here are substantially colder than the reference temperature $(263 \mathrm{~K})$ and that pressure is substantially smaller than the methanol triple point pressure $(0.18 \mathrm{~Pa})$. Arrows show the direction of the subprocesses described in the text, and thin black lines show the process path. $T_{\text {sat }}$ is the methanol solid-vapor coexistence temperature corresponding to $0.01 \mathrm{~Pa}$. 
Table 3. Analysis of the Process Shown in Figure 6 for the Seven Tested Alkanols ${ }^{\mathrm{a}}$

\begin{tabular}{|c|c|c|c|c|c|c|}
\hline Compound & $\Delta G_{g, s s}^{263}, \mathrm{~J} / \mathrm{mol}$ & $\Delta G_{a} /\left|\Delta G_{g, s s}^{263}\right|$ & $\Delta G_{c} /\left|\Delta G_{g, s s}^{263}\right|$ & $\Delta G_{d} /\left|\Delta G_{g, s s}^{263}\right|$ & $\Delta G_{e} /\left|\Delta G_{g, s s}^{263}\right|$ & $\Delta G_{f} \mid \Delta G_{g, s s}^{263}$ \\
\hline Methanol & -2440 & 15.1 & 0.1 & -5.8 & -13.7 & 3.3 \\
\hline Ethanol & -1680 & 22.2 & -0.2 & -9.7 & -20.4 & 7.1 \\
\hline n-propanol & -2310 & 16.9 & -0.4 & -8.1 & -14.6 & 5.2 \\
\hline n-butanol & -1130 & 29.7 & -0.3 & -14.8 & -30.7 & 15.2 \\
\hline tert-butanol & -3620 & 11.6 & 0.8 & -6.1 & -8.9 & 1.6 \\
\hline Cyclohexanol & -2630 & 8.4 & 0.2 & -3.8 & -12.7 & 6.9 \\
\hline
\end{tabular}

${ }^{\mathrm{a}} \Delta G_{g, s s}^{263}$ is Gibbs energy for the overall process calculated as $\Delta G_{g, s s}^{263}=-\mathrm{RT}_{i} \ln K_{g, s s}^{263}$, where $T_{i}$ is the reference temperature (263 K). $\Delta G_{a, c, d, e f}$ are the contributions to the overall Gibbs free energy change corresponding to subprocesses "a" and "c-f." See text for details.

from $K_{g, s s}^{263}$ and analyte partial pressure, and assumed that analyte/water liquid mixture is ideal. Hence

$$
\Delta G_{e}=R T_{i}\left(\frac{X_{1}}{X_{2}} \ln \left(X_{1}\right)+\ln \left(X_{2}\right)\right)
$$

The values of $\Delta G_{f}$ were computed by differencing $\Delta G_{g, \mathrm{ss}}^{263}$, evaluated as $\Delta G_{g, \mathrm{ss}}^{263}=-R T_{i} \ln K_{g, \mathrm{ss}}^{263}$, and the sum of the Gibbs free energy changes for subprocesses "a," "c," "d," "e," and "f." Subprocess "b" is excluded from the sum, and from Table 3 because it is analyzed as an equilibrium phase transition, and thus $\Delta G_{b}$ is zero.

[46] Table 3 shows that subprocess "e" makes a substantial contribution to the overall Gibbs energy change, and that subprocesses "a" and "d" also play a role in determining the magnitude of $\Delta G_{g, \mathrm{ss}}^{263}$. For subprocesses "a" and " $d$ " we have formulated Gibbs free energy change by employing an expression developed by Fuchs [1996]:

$$
\begin{gathered}
\Delta G_{a}=C_{p}\left[\left(T_{\text {sat }}-T_{i}\right)-T_{\text {sat }} \ln \left(T_{\text {sat }} / T_{i}\right)\right]-\left(T_{\text {sat }}-T_{i}\right) S_{g} \\
\Delta G_{d}=C_{l}\left[\left(T_{i}-T_{\text {sat }}\right)-T_{i} \ln \left(T_{i} / T_{\text {sat }}\right)\right]-\left(T_{i}-T_{\text {sat }}\right) S_{l} .
\end{gathered}
$$

Here $C_{p}$ is the constant pressure heat capacity for gaseous alkanol, $C_{l}$ is the heat capacity of alkanol liquid and $S_{g}$ and $S_{l}$ are the entropies of gaseous and liquid alkanol. For our assessments of $\Delta G_{a}$ and $\Delta G_{d}$ we utilize constant values of $C_{p}$ [Stull et al., 1969] and $C_{l}$ [Arnett et al., 1969] evaluated at $298 \mathrm{~K}$, values of $S_{l}$ at $298 \mathrm{~K}$ adjusted to $T_{i}$ [Stull et al., 1969], and values of $S_{g}$ at $298 \mathrm{~K}$ and 1 atm adjusted to $T_{i}$ and $P_{i}$ [Stull et al., 1969]. The terms proportional to entropy on the right hand sides of equations (7) and (8) are dominant. Elimination of the higher-order terms in equations (7) and (8), summation of equations (7) and (8) with $\Delta G_{b}, \Delta G_{e}$ and $\Delta G_{f}$, and the approximation $S_{g}-S_{l} \approx$ $\Delta H_{\mathrm{vap}}^{298} / T_{\text {sat }}$, leads to the result which is the basis for the $K_{g, \text { ss }}^{263} / \Delta H_{\text {vap }}^{298}$ fitting function:

$$
\Delta G_{g, \mathrm{ss}}^{263} \approx\left(\left(T_{i}-T_{\mathrm{sat}}\right) / T_{\mathrm{sat}}\right) \Delta H_{\mathrm{vap}}^{298}+\Delta G_{b}+\Delta G_{e}+\Delta G_{f} .
$$

[47] To construct the fit shown in Figure 5 we regressed $\Delta G_{g, \mathrm{ss}}^{263}$, evaluated as $\Delta G_{g, \mathrm{ss}}^{263}=-R T_{i} \ln K_{g, \mathrm{ss}}^{263}$, and values of the heat of vaporization at $298 \mathrm{~K}$ [Stull et al., 1969]. Best-fit coefficients corresponding to the form $\Delta G_{g, \mathrm{ss}}^{263}=c_{1}+c_{2}$. $\Delta H_{\text {vap }}^{298}$ are $c_{1}=-6.9 \times 10^{3} \pm 5.4 \times 10^{3} \mathrm{~J} / \mathrm{mol}$ and $c_{2}=0.11$ \pm 0.12 . The best-fit line was computed as $K_{g, \mathrm{ss}}^{263}=\exp \left(-\left(c_{1}\right.\right.$ $\left.\left.+c_{2} \Delta H_{\text {vap }}^{298}\right) /\left(R T_{i}\right)\right)$. Further experimental work is needed to check the predictive ab f $K_{g, s s}^{263} / \Delta H_{\text {vap }}^{298}$ fitting function for other alkanols, and to see if data for ketones define a separate curve in this coordinate frame as is anticipated from the fact that the acetone data point plots substantially below the alkanol curve.

\section{Atmospheric Implications}

[48] In Appendix A we develop temperature-dependent uptake coefficients corresponding to four pathways: (1) analyte plus water vapor codeposition, (2) uptake by ice assumed to behave like liquid water, (3) uptake into liquid solution, and (4) bonding to the ice-air interface. For the latter pathway, referred to as surface uptake, we use data from Sokolov and Abbatt [2002] to characterize the analyte/ ice surface interaction. The Sokolov and Abbatt [2002] surface uptake coefficients were converted to effective volume uptake coefficients via the upper limit and lower limit ice-specific surface areas reported by Hoff et al. [1998] (370 and $60 \mathrm{~m}^{2} / \mathrm{kg}$ ). We assume that this range of specific surface areas is representative of our samples. For the pathway mediated by liquid solution coexisting with ice, and assumed to be confined to the ice-air interface [Conklin and Bales, 1993], we employ the temperature-dependent measurements of liquid water volume fraction reported by Conklin and Bales [1993]. We refer to this pathway as the liquid layer model.

[49] The predictions and our data are shown for ethanol and n-butanol in Figures $7 \mathrm{a}$ and $7 \mathrm{~b}$, respectively. Figure $7 \mathrm{a}$ shows that the codeposition and Henry's law pathways both strongly overestimate the ethanol observations, and that surface uptake may be competitive at temperatures colder than $-20^{\circ} \mathrm{C}$, particularly if our ice-specific surface areas were greater than $370 \mathrm{~m}^{2} / \mathrm{kg}$. The n-butanol data (Figure $7 \mathrm{~b}$ ) also diverges from the codeposition and Henry's Law predictions. This is also true for our methanol and n-propanol data (not shown). Compared to Figure 7a, the Figure $7 \mathrm{~b}$ shows a shift of the surface uptake prediction to warmer temperatures where it overlaps with our data in the $-10^{\circ}$ to $-20^{\circ} \mathrm{C}$ temperature range. This shift reflects the larger affinity of n-butanol for ice surfaces compared to that of ethanol [Sokolov and Abbatt, 2002]. However, for none of the $\mathrm{C}_{1}-\mathrm{C}_{4}$ normal alkanols is there strong evidence of a reversal temperature indicative of surface uptake dominating at cold temperatures. Such a reversal is expected because of the negative temperature dependence of ice/ alkanol surface uptake coefficients [Sokolov and Abbatt, 2002]. The lack of a pronounced reversal temperature suggests that our samples were characterized by specific surface areas substantially smaller than that measured by Hoff et al. [1998] or that the temperature-extrapolated 

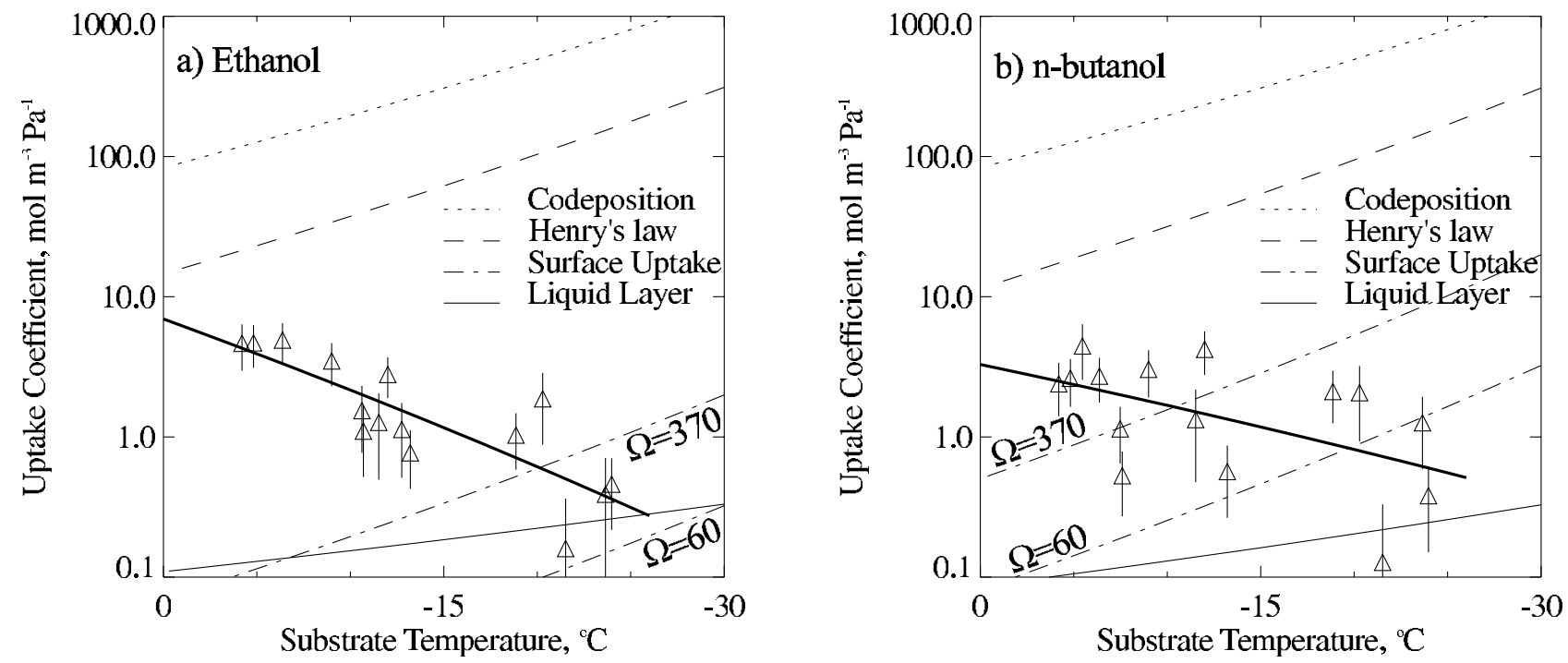

Figure 7. Measured, predicted, and effective volume uptake coefficients for (a) ethanol and (b) n-butanol. The codeposition, Henry's law, surface uptake, and liquid layer models are described in the text. The bold curve is the Van't Hoff fitting function. Uncertainties were calculated using the measurement errors discussed in sections 2.6 and 2.7 and an error propagation equation based on equations (2) and (3). Surface uptake is represented as an effective volume uptake coefficient using the upper limit and lower limit ice-specific surface areas reported by Hoff et al. [1998] $(\Omega=370$ and $\Omega=$ $60 \mathrm{~m}^{2} / \mathrm{kg}$ ) and equation (A4). Uptake into a surface liquid layer is represented as an effective volume uptake coefficient (equation (A5)).

Sokolov and Abbatt [2002] surface uptake coefficients are not applicable to the conditions of our experiment. The most obvious difference is temperature, $-4^{\circ}$ to $-24^{\circ} \mathrm{C}$ for our work versus $-40^{\circ}$ to $-60^{\circ} \mathrm{C}$ for Sokolov and Abbatt's [2002] characterizations of ethanol and n-butanol surface uptake, the fact that our ice surfaces were growing whereas Sokolov and Abbatt studied ice surfaces which were at dynamic equilibrium (static ice) and the possibility that analyte desorption occurred during sample transfer (section 2.6).

[50] Figure 7 shows that the codeposition, Henry's law, surface uptake and liquid layer pathways are characterized by a negative temperature dependence and that this is opposite the positive temperature dependence of our uptake measurements. Understanding of this temperature dependence is needed to describe the budgets of some tropospheric species. Crutzen and Lawrence [2000] showed that a volume uptake coefficient larger than $10 \mathrm{~mol} \mathrm{~m}^{-3} \mathrm{~Pa}^{-1}$ is necessary for precipitation to make a substantial contribution to the removal of a gaseous tropospheric constituent. Results shown in Figure 4 and in Table 1 indicate that the Crutzen and Lawrence threshold is not exceeded for the studied oxyhydrocarbons. The inference is that ambient concentrations of these compounds will not be perturbed by uptake into ice formed by vapor deposition. However, our data do suggest that at $0^{\circ} \mathrm{C}$ the $\mathrm{C}_{1}-\mathrm{C}_{4}$ alkanol water/solid solution partition coefficients are substantial $\left(K_{l, \mathrm{ss}} \approx 0.5\right)$ as can be inferred by ratioing the $y$ intercept of the data fitting curve to the $y$ intercept of the Henry's law curve (Figure 7). Since Snider and Huang [1998] argue that $K_{l, \mathrm{ss}}$ represents a lower bound for the riming retention efficiency, our results suggest that alkanol uptake during riming may be efficient enough to exceed the $10 \mathrm{~mol} \mathrm{~m}^{-3}$ hreshold proposed by Crutzen and Lawrence [2000], particularly for riming occurring at temperatures colder than $-10^{\circ} \mathrm{C}$.

\section{Conclusions}

[51] This work was motivated by a need for experimental information regarding gas uptake by ice forming via vapor deposition. Two significant results come from this study. First, our analysis of $\mathrm{C}_{1}-\mathrm{C}_{4}$ alkanol volume uptake indicates that these compounds weaken water-water bonding when incorporated into ice. That assertion is based on the positive temperature dependence of the volume uptake coefficient and is corroborated by indirect estimates of the effect of the alkanols on ice saturation vapor pressure. The effect on ice saturation vapor pressure is unexpected and worthy of validation by other techniques. However, the departures from ideality we document (i.e., ice saturation vapor depression factors smaller than unity) are unlikely to have significant implications for saturation vapor pressures, principally because the Raoult effect is negligible for tropospheric ice particles. Second, our volume uptake coefficients exhibit a temperature dependence that is opposite that predicted by four models of gas scavenging. At temperatures colder than approximately $-10^{\circ} \mathrm{C}$ our data do overlap with model predictions describing analyte bonding to the ice-air interface (surface uptake), and at temperatures colder than approximately $-20^{\circ} \mathrm{C}$ there is overlap with the model describing uptake into a surface liquid layer. However, the significance of those overlaps depends on ice-specific surface area and the volume of solution associated with the liquid layer. Neither of these parameters was measured during our study and thus improved understanding of gas/ice interaction 
phenomena will require coordinated measurement of these other relevant parameters.

\section{Appendix A: Uptake Models}

[52] We define codeposition as a process which produces ice having the same molar proportions of analyte and $\mathrm{H}_{2} \mathrm{O}$ as exist in the gas phase. This approach was proposed by Jacob and Klockow [1993] who conducted concurrent atmospheric measurements of ice-bound and gas-phase $\mathrm{H}_{2} \mathrm{O}_{2}$. The volume uptake coefficient corresponding to codeposition is defined as

$$
K_{\mathrm{cod}}=\frac{\rho_{i}}{e_{i}(T) \mathrm{MW}_{w}}
$$

where $\rho_{i}$ is the bulk density of ice, $e_{i}(T)$ is the $\mathrm{H}_{2} \mathrm{O}$ saturation partial pressure over ice and $\mathrm{MW}_{w}$ is the molecular weight of water. Implicit in this formulation is the assumption that the mass accommodation coefficients for the water vapor and gaseous analyte are equal.

[53] Henry's law coefficients, often extrapolated to temperatures colder than $0^{\circ} \mathrm{C}$, are used to describe gas scavenging in some model simulations of tropospheric chemistry [e.g., Kanakidou et al., 1991]. Using data from Snider and Dawson [1985], the Henry's Law coefficient is

$$
K_{g, l}=\frac{\Psi_{g, l}^{0}}{R T} \exp \left(\frac{-\Delta H_{\mathrm{tr}}}{R}\left(1 / T-1 / T_{0}\right)\right)
$$

where $\Psi_{g, l}^{0}$ is a dimensionless Henry's law coefficient evaluated at a reference temperature $\left(T_{0}=273 \mathrm{~K}\right)$ and $\Delta H_{\mathrm{tr}}$ is the reaction enthalpy corresponding to the gas-toliquid transfer. On the assumption that analytes are partitioned into ice as described by their interaction with liquid water, the volume uptake coefficient is equivalent to the Henry's law coefficient. Following this assumption, the volume uptake coefficient is

$$
K_{\text {hen }}=K_{g, l}
$$

[54] Sokolov and Abbatt [2002] measured surface uptake coefficients of several organic compounds at temperatures colder than $-32^{\circ} \mathrm{C}$. Their results are most complete for ethanol and n-butanol, but this data is confined to the $-60^{\circ} \mathrm{C}$ to $-40^{\circ} \mathrm{C}$ interval. The reaction enthalpies $\left(\Delta H_{a}\right)$ they report were used to infer temperature-dependent surface uptake coefficients $\left(K_{\text {surf }}\left(T, \Delta H_{\mathrm{a}}\right), \mathrm{mol} \mathrm{m}^{-2} \mathrm{~Pa}^{-1}\right)$. The latter was used to represent surface uptake as an effective volume uptake coefficient:

$$
K_{\text {ads }}=K_{\text {surf }}\left(T, \Delta H_{a}\right) \Omega \rho_{i} .
$$

Here $\Omega$ is ice surface area specific to $1 \mathrm{~kg}$. In Figure 7 we assume the upper and lower limits of $\Omega$ are 370 and $60 \mathrm{~m}^{2} / \mathrm{kg}$. These extremes bound measurements reported Hoff et al. [1998] and encompass specific surface area values for both rimed and unrimed snow, reported by Dominé et al. [2001], and five of six measurements of hoar frost specific surface area reported by Hanot and Dominé [1999].
[55] The effective volume uptake coefficient corresponding to uptake into a liquid layer was estimated as

$$
K_{\mathrm{LL}}=f_{w}(T) K_{g, l}(T)
$$

Here $f_{w}$ is the liquid water volume fraction in ice. Data from Conklin and Bales [1993] for ice samples prepared by freezing aqueous solutions containing $10^{-5} \mathrm{M} \mathrm{NaCl}$ were used to formulate a best-fit relationship between $f_{w}$ and $T$.

\section{Notation}

$C_{l}$ heat capacity of pure liquid alkanol.

$C_{p}$ isobaric heat capacity of pure gaseous alkanol.

$e_{i}(T)$ saturation vapor pressure over pure ice.

$f_{w}$ liquid water volume fraction in ice.

$K_{l, \mathrm{ss}}$ water-to-solid solution partition coefficient.

$K_{g \text {,ss }}$ gas-to-solid solution volume uptake coefficient.

$K_{g, l}$ gas-to-liquid water partition coefficient (i.e., the Henry's law constant).

$K_{\text {surf }}$ gas-to-ice surface uptake coefficient.

$m_{i}$ mass of ice.

$\mathrm{MW}_{w}$ molecular weight of water.

$n_{a}$ analyte amount in ice.

$P_{a}$ analyte partial pressure.

$R$ universal gas constant.

$S_{g}$ entropy of gas.

$S_{l}$ entropy of liquid.

$T$ temperature.

$T_{\text {sat }}$ coexistence temperature for solid and gaseous alkanol.

$\Delta G$ reaction Gibbs free energy.

$\Delta H$ reaction enthalpy.

$\Psi_{g, l}$ dimensionless Henry's law coefficient.

$\Omega$ specific surface area.

$\rho_{i}$ bulk ice density.

[56] Acknowledgments. The authors acknowledge insightful discussions with Marc Valdez, Derek Montague and Markus Petters. This work was supported by a grant from the National Science Foundation, ATM-9314358, and by support for William A. Huffman coming from the NASA Wyoming Space Grant Consortium. Technical assistance from Donal Lukens and Perry Wechsler is appreciated.

\section{References}

Altshuller, A. P., and I. R. Cohen (1960), Application of diffusion cells to the production of known concentrations of gaseous hydrocarbons, Anal. Chem., 32, 802-810.

Arnett, E. M., W. B. Kover, and J. V. Carter (1969), Heat capacities of organic compounds in solution. I. Low molecular weight alcohols in water, J. Am. Chem. Soc., 91, 4028-4034.

Avila, E. E., R. G. Pereyra, N. E. Castellano, and C. P. R. Saunders (2001), Ventilation coefficients for cylindrical collectors growing by riming as a function of cloud droplet spectra, Atmos. Res., 57, 139-150.

Benkelberg, H.-J., S. Hamm, and P. Warneck (1995), Henry's law coefficients for aqueous solutions of acetone, acetaldehyde and acetonitrile, and equilibrium constants for the addition compounds of acetone and acetaldehyde with bisulfite, J. Atmos. Chem., 20, 17-34.

Conklin, M. H., and R. C. Bales (1993), $\mathrm{SO}_{2}$ uptake on ice spheres: Liquid nature of the ice-air interface, J. Geophys. Res., 98, 16,851-16,855.

Conklin, M. H., A. Sigg, A. Neftel, and R. C. Bales (1993), Atmospheresnow transfer function for $\mathrm{H}_{2} \mathrm{O}_{2}$ : Microphysical considerations, J. Geophys. Res., 98, 18,367-18,376.

Crutzen, P. J., and M. G. Lawrence (2000), The impact of precipitation scavenging on the transport of trace gases: A 3-dimensional model sensitivity study, J. Atmos. Chem., 37, 81-112.

Dominé, F., and E. Thibert (1996), Mechanism of incorporation of trace gases in ice grown from the gas phase, Geophys. Res. Lett., 23, $3627-$ 3630 . 
Dominé, F., A. Cabanes, A.-S. Taillandier, and L. Legagneux (2001), Specific surface area of snow samples determined by $\mathrm{CH}_{4}$ adsorption at $77 \mathrm{~K}$ and estimated by optical microscopy and scanning electron microscopy, Environ. Sci. Technol., 35, 771-780.

Fletcher, N. H. (1970), The Chemical Physics of Ice, Cambridge Univ. Press, New York.

Fuchs, H. U. (1996), The Dynamics of Heat, Springer-Verlag, New York.

Goldan, P. D., W. C. Kuster, and F. C. Fehsenfeld (1995), Hydrocarbon measurements in the southeastern United States: The Rural Oxidants in the Southern Environment (ROSE) Program 1990, J. Geophys. Res., 100, $25,945-25,963$

Goss, K.-U. (1993), Adsorption of organic vapors on ice and quartz sand at temperatures below $0^{\circ} \mathrm{C}$, Environ. Sci. Technol., 27, 2826-2830.

Goss, K.-U. (1994), Adsorption of organic vapors on polar mineral surfaces and on bulk water surfaces: Development of an empirical predictive model, Environ. Sci. Technol., 28, 640-645.

Hanot, L., and F. Dominé (1999), Evolution of the surface area of a snow layer, Environ. Sci. Technol., 33, 4250-4255.

Hanson, D., and K. Mauersberger (1988), Solubility and equilibrium vapor pressures of $\mathrm{HCl}$ dissolved in polar stratospheric cloud materials: Ice and the trihydrate of nitric acid, Geophys. Res. Lett., 15, 1507-1510.

Hanson, D., and K. Mauersberger (1990), $\mathrm{HCl} / \mathrm{H}_{2} \mathrm{O}$ solid phase vapor pressures and $\mathrm{HCl}$ solubility in ice, J. Phys. Chem., 94, 4700-4705.

Hobbs, P. V. (1978), Organization and structure of clouds and precipitation on the mesoscale and microscale in cyclonic storms, Rev. Geophys., 16, $741-755$.

Hoff, J. T., D. Gregor, D. MacKay, F. Wania, and C. Q. Jia (1998), Measurement of the specific surface area of snow with the nitrogen adsorption technique, Environ. Sci. Technol., 32, 58-62.

Houze, R. A., Jr. (1993), Cloud Dynamics, Academic, San Diego, Calif.

Hudson, P. K., M. A. Zondlo, and M. A. Tolbert (2002), The interaction of methanol, acetone and acetaldehyde with ice nitric acid-doped ice: Implications for cirrus clouds, J. Phys. Chem. A, 106, 2882-2888.

Huffman, W. A. (1999), An investigation of the uptake of low-molecular weight oxygenated hydrocarbons during vapor depositional growth, $\mathrm{Ph}$.D. thesis, Univ. of Wyoming, Laramie.

Jacob, P., and D. Klockow (1993), Measurements of hydrogen peroxide in Antarctic ambient air, snow and firm cores, Fresenius Z. Anal. Chem. 346, 429-434.

Jayne, J. T., S. X. Duan, P. Davidovits, D. R. Worsnop, M. S. Zahnniser, and C. E. Kolb (1991), Uptake of gas-phase alcohol and organic acid molecules by water surfaces, J. Phys. Chem., 95, 6329-6336.

Kamlet, M. J., R. M. Doherty, M. H. Abraham, Y. Marcus, and R. W. Taft (1988), Linear solvation energy relationships. 46. An improved equation for correlation and prediction of octanol/water partition coefficients of organic nonelectrolytes (including strong hydrogen bond donor solutes), J. Phys. Chem., 92, 5244-5255.
Kanakidou, M., H. B. Singh, K. M. Valentin, and P. J. Crutzen (1991), A two-dimensional study of ethane and propane oxidation in the troposphere, J. Geophys. Res., 96, 15,395-15,413.

Knight, C. A. (1996), Surface layers on ice, J. Geophys. Res., 101, 12,92112,928 .

List, R. J. (1984), Smithsonian Meteorological Tables, Smithsonian Inst., Washington, D. C.

Lugg, G. A. (1968), Diffusion coefficients of some organic and other vapors in air, Anal. Chem., 40, 1072-1080.

Mitra, S. K., S. Barth, and H. R. Pruppacher (1990), A laboratory study of the scavenging of $\mathrm{SO}_{2}$ by snow crystals, Atmos. Environ., Part A, 24, $2307-2312$.

Reif, F. (1965), Fundamentals of Statistical and Thermal Physics, McGrawHill, New York.

Schaeffer, V. J., and R. J. Cheng (1971), The production of ice crystal fragments by sublimation and electrification, J. Rech. Atmos., 5, 5-10.

Singh, H. B., D. O'Hara, D. Herlth, W. Sachse, D. R. Blake, J. D. Bradshaw, M. Kanakidou, and P. J. Crutzen (1994), Acetone in the atmosphere: Distribution, sources, and sinks, J. Geophys. Res., 99, $1805-1819$

Snider, J. R., and G. A. Dawson (1985), Tropospheric light alcohols, carbonyls, and acetonitrile: Concentrations in the southwestern United States and Henry's law data, J. Geophys. Res., 90, 3797-3805.

Snider, J. R., and J. Huang (1998), Factors influencing the retention of hydrogen peroxide and molecular oxygen in rime ice, J. Geophys. Res., 103, $1405-1415$

Sokolov, O., and J. P. D. Abbatt (2002), Adsorption to ice of n-alcohols (ethanol to 1-hexanol), acetic acid, and hexanal, J. Phys. Chem. A, 106, $775-783$.

Stephenson, R. M., and S. Malanowski (1987), Handbook of the Thermodynamics of Organic Compounds, Elsevier Sci., New York.

Stull, D. R., E. R. Westrum Jr., and G. C. Sinke (1969), The Chemical Thermodynamics of Organic Compounds, John Wiley, Hoboken, N. J.

Valdez, M. P., G. A. Dawson, and R. C. Bales (1989), Sulfur dioxide incorporation into ice depositing from the vapor, J. Geophys. Res., 94, $1095-1103$.

Van Ness, H. C., and M. M. Abbott (1978), Liquid-vapor equilibrium and excess Gibbs energy: Acetone + methanol, + ethanol, or + methyl acetate binary mixtures, Selec. Data Mixtures, 1978, 65-73.

W. A. Huffman, Huffman Laboratories, Incorporated, 4630 Indiana Street, Golden, CO 80403, USA. (bhuffman@huffmanlabs.com)

J. R. Snider, Department of Atmospheric Sciences, University of Wyoming, P.O. Box 3038, Laramie, WY 82701, USA. (jsnider@uwyo. edu) 